\section{InIIret}

2.2021

Nuria Pastor Muñoz

Universidad Pompeu Fabra

\title{
El legado de Gustav Radbruch para la dogmática jurídico-penal
}

\begin{abstract}
Sumario
El presente trabajo aborda algunos aspectos del pensamiento de Gustav Radbruch que han dejado una impronta esencial en nuestro modo de concebir la dogmática jurídico-penal. En concreto, analiza la compleja relación entre Derecho, realidad y valor en la concepción de Radbruch, la impronta de su método y su relativismo valorativo en el Derecho penal, su concepción de la teoría del delito y de la ciencia jurídico-penal. El estudio concluye destacando la herencia que este autor ha dejado a la dogmática jurídico-penal del presente: la vuelta al valor, la orientación teleológica, el sistema abierto y la superación de la oposición entre dogmática y política criminal, entre otros aspectos.
\end{abstract}

\begin{abstract}
This article examines some aspects of Gustav Radbruch's views that have significantly shaped our understanding of criminal law dogmatics. In particular, the complex relationship between law, reality, and value in Radbruch's conception, the impact of his method and relativism in criminal law, his conception of the theory of crime, and the science of criminal law are discussed. Finally, the article highlights the contents of the legacy that Gustav Radbruch left to criminal law dogmatics: the return to value, the teleological orientation, the open system and the overcoming of the opposition between dogmatics and criminal policy, among other aspects.
\end{abstract}

\begin{abstract}
Der vorliegende Beitrag befasst sich mit einigen Aspekten des Denkens Gustav Radbruchs, die unser Verständnis der Strafrechtsdogmatik wesentlich geprägt haben. Insbesondere wird hier das komplexe Verhältnis von Recht, Wirklichkeit und Wert in Radbruchs Konzeption, die Spuren seiner Methode und seines Relativismus in dem Strafrecht, seine Konzeption der Straftatlehre und der Strafrechtswissenschaft. Schließend hebt der Beitrag die Inhalte der Erbe, die Gustav Radbruch der Strafrechtsdogmatik hinterlassen hat: die Rückkehr zu dem Wert, die teleologische Orientierung, das offene System und die Überwindung des Gegensatzes zwischen Dogmatik und Kriminalpolitik, neben anderen Aspekten.
\end{abstract}

Title: Gustav Radbruch's Legacy to Criminal Law Dogmatics

Titel: Gustav Radbruchs Erbe für die Strafrechtsdogmatik

Palabras clave: dualismo metodológico, valor, relativismo, teoría del delito, sistema abierto del delito, dogmática jurídico-penal

Keywords: methodological dualism, value, relativism, theory of the crime, open construction of the crime, criminal law dogmatic (sciencie)

Stichwörter: Methodendualismus, Wert, Relativismus, Straftatlehre, offenes Straftatsystem, Strafrechtsdogmatik

DOI: 10.31009/InDret.2021.i2.03 
InI)ret

2.2021

Recepción

$27 / 10 / 2020$

Aceptación

$24 / 12 / 2020$

Índice

\section{Introducción}

2. Derecho, realidad y valor en la teoría de Radbruch

2.1. El trialismo metodológico

2.2. La naturaleza de las cosas

2.3. La idea de Derecho

2.4. El relativismo valorativo en Radbruch

3. La impronta del método y del relativismo valorativo de Radbruch en una visión valorativa del Derecho penal

4. La visión de Radbruch de teoría del delito y la dogmática jurídico-penal

4.1. La naturaleza de las cosas en la construcción de la teoría del delito

4.2. El rechazo del formalismo y del positivismo hermenéutico

4.3. La relación entre ciencia jurídica y Derecho positivo

4.4. El sistema del delito como sistema abierto: de los conceptos clasificatorios a los "Typenbegriffe"

5. Balance: la herencia de Radbruch para la dogmática jurídico-penal

5.1. La vuelta del valor a la dogmática y la orientación teleológica

5.2. Las raíces del sistema abierto de Roxin en la concepción de Radbruch

5.3. El puente entre Derecho continental y Derecho anglosajón

5.4. La superación de la oposición entre dogmática y política criminal

5.5. El problema (de Radbruch y de la dogmática del presente) de los

"valores” de referencia en la construcción dogmática

5.6. ¿"Autolimitación” de la dogmática a un Derecho positivo concreto?

6. Bibliografía

Este trabajo se publica con una licencia Creative Commons Reconocimiento-No Comercial 4.0 Internacional @) (1) (9) 


\section{Introducción}

La figura de Gustav RADBRUCH es un referente indiscutible en la Filosofía del Derecho, así como en Derecho penal. Su Rechtsphilosophie ${ }^{1}$ (su revisión del paradigma metodológico kantiano), su conocida "fórmula", ${ }^{2}$ clave en la discusión sobre el valor del Derecho positivo, y su habilitación sobre el concepto jurídico-penal de acción ${ }^{3}$ son obras esenciales. En Derecho penal, su relevancia no se limita a dicho escrito de habilitación, sino que su visión especial del neokantismo ("trialismo metodológico"), sus reflexiones sobre el papel de la naturaleza de las cosas, el valor en el Derecho, el relativismo, así como la crítica al sistema clasificatorio y construcción de un sistema teleológico han dejado huellas profundas en la dogmática jurídico-penal. Se puede anunciar ya aquí que la herencia más importante de RADBRUCH para la dogmática jurídico-penal proviene esencialmente de su época neokantiana: por una parte, una comprensión de la dogmática jurídico-penal que, sin dejar de ser sistemática, abandona el hermetismo y se abre a la realidad (a la naturaleza de las cosas); por otra, la entrada del valor en el Derecho a partir de una reformulación del dualismo metodológico. Dichas aportaciones, que abordaré después con más detalle, tienen sus raíces en su peculiar modo de concebir la relación entre Derecho, valor y realidad: el trialismo metodológico, el papel de la naturaleza de las cosas, su relativismo valorativo (II) y sus consecuencias para el Derecho penal (III). A ello se une su concepción de la dogmática, el rechazo del formalismo y el positivismo hermenéutico y la concepción del sistema como sistema "abierto" (IV). El balance que arroja este análisis es una rica herencia para la ciencia jurídico-penal que tiene sus luces y sus sombras: sus luces, porque pone algunos cimientos de la concepción normativista del delito (la impronta en Roxin es innegable) y sus sombras, porque genera algunos problemas (en especial, en torno al "valor") que seguimos arrastrando en el presente $(\mathrm{V})$.

\section{Derecho, realidad y valor en la teoría de Radbruch}

\subsection{El trialismo metodológico}

En cualquier concepción del Derecho resulta esencial determinar cuál es la relación entre la idea de Derecho y la materia del Derecho y, con ello, si el Derecho se construye deductiva o inductivamente. Pues bien, por una parte, RADBRUCH rechaza aquellas teorías iusnaturalistas que niegan relevancia a la materia del Derecho (Rechtsstoff) y pretenden construir el ordenamiento jurídico deductivamente a partir de la idea de Derecho. ${ }^{4}$ Pero a la vez, por otra parte, rechaza la explicación materialista de la Historia, la cual niega cualquier autonomía al Derecho, vaciándolo

\footnotetext{
${ }^{1}$ Aquí se citará la segunda edición.

2 RADBRUCH, «Gesetzliches Unrecht und übergesetzliches Recht, Süddeutsche Juristenzeitung (1946)», en Dreier/PaUlson (eds.), Studienausgabe, $2^{\mathrm{a}}$ ed., 2003, pp. 211 ss.

${ }^{3}$ RADBRUCH, Der Handlungsbegriff in seiner Bedeutung für das Strafrechtssystem, 1903.

${ }^{4}$ RADBRUCH, Vorschule der Rechtsphilosophie: Nachschrift einer Vorlesung, 2a ed., 1959, pp. 84 ss. En efecto, según la teoría del Derecho natural, „Die Idee des Rechts hat (...) die uneingeschränkte Herrschaft über den Stoff, ja sie findet einen Rechtsstoff überhaupt nicht vor. Sie [die Naturrechtslehre] geht nicht von einer bestimmten historischen Lage aus, die das Recht zu gestalten hat, sondern von einem angeblichen Naturzustand“. Así, las formas de la vida social no preexistirían al Derecho, sino que este las crearía, con lo que - subraya RADBRUCH - se niega la resistencia de la materia del Derecho (Widerstandskraft des Rechtsstoffes), el carácter transformable del Derecho (Wandelbarkeit des Rechts) vinculado a la dimensión histórica del Derecho y, con ello, se acepta una "dictadura” de la Rechtsidee sobre el Rechtsstoff.
} 
de contenido y convirtiéndolo en un mero receptor de la materia del Derecho, esto es, en el mero producto de la evolución histórica y económica. ${ }^{5}$ Para RADBRUCH, el Derecho no se debe definir partiendo del imperio del deber ser sobre el ser (iusnaturalismo) ni tampoco asumiendo el imperio del ser sobre el deber ser (marxismo): el Derecho es una obra humana, manifestación de la cultura, y por ello está necesariamente referido al valor (wertbezogen), sin que pueda ser construido desde la perspectiva valorativamente neutra (wertblinde Haltung) de las ciencias naturales. ${ }^{6}$ Lo más importante de su concepción del dualismo metodológico es el levantamiento de la separación entre el ser y el deber ser, mediante la construcción de un puente entre ambos: la "naturaleza de las cosas" (die Natur der Sache). ${ }^{7}$ Esta modificación es tan sustancial, que algunos han denominado "trialismo metodológico", ${ }^{8}$ el cual no implica que el ser y el deber ser se diluyan, pero sí la relajación ${ }^{9}$ de la separación radical entre ambos propia del pensamiento kantiano. ${ }^{10}$ Así, afirma RADBRUCH: "La naturaleza de las cosas es la solución para todos aquellos que quieren mitigar el abrupto dualismo de ser y deber ser, de realidad y valor, aquellos que buscan la razón en las cosas". ${ }^{11}$ La naturaleza de las cosas ofrece resistencia al deber ser, limita la autonomía de este último, aunque no la elimina ("la última palabra la tiene el Derecho"). ${ }^{12}$ Con ello, en RADBRUCH el deber ser deja de ser hermético y se abre a la realidad, algo que se proyectará en su concepción de la dogmática jurídico-penal. Además, como consecuencia de la negación de la separación radical entre ser y deber ser, RADBRUCH se aleja del paradigma positivista: Derecho positivo y valoración ética están separados, pero existe un puente entre ambos, por ser el Derecho una "realidad referida al valor" (wertbezogene Wirklichkeit); el Derecho positivo no se identifica con lo justo o lo correcto, pero se orienta a la justicia. ${ }^{13}$

\subsection{La naturaleza de las cosas}

RADBRUCH toma como punto de partida la premisa del dualismo metodológico conforme a la cual del ser no surge el deber ser, siendo el primero el mundo de la realidad y el segundo el mundo de

\footnotetext{
${ }^{5}$ Aquí habría una "dictadura” de la Rechtsstoff sobre la Rechtsform. Sobre las diferencias entre RADBRUCH y el marxismo, cfr. PAUL, «Gustav Radbruchs Konzeption des sozialen Rechts und die marxistische Rechtstheorie”, en KAUfMANN, Arthur (ed.), Gedächtnisschrift für Gustav Radbruch, 21.11.1878-23.11.1949, 1968, pp. 114 ss. Cfr. un análisis crítico del materialismo histórico en RADBRUCH, Rechtsphilosophie. Studienausgaben, 2003, § 3, núm. 4, pp. 25 s.

${ }^{6}$ RADBRUCH, Rechtsphilosophie, 2003, § 4, pp. 9, 11.

${ }^{7}$ NEUMANN, «Rechtsphilosophie im Spiegel der Zeit: Gustav Radbruch (1878-1949)», JZ, (1), 2020, p. 5.

${ }^{8}$ RADBRUCH, Rechtsphilosophie, 2003, § 3, núm. 9, p. 31. Una dura crítica al dualismo metodológico kantiano, fuertemente anclado en la ciencia jurídica en Arthur KAUFMANN, «Die »ipsa res iusta«. Gedanken zu einer hermeneutischen Rechtsontologie», en EL MISMO, Beiträge zur juristischen Hermeneutik sowie weitere rechtsphilosophische Abhandlungen, $2^{\mathrm{a}}$ ed., 1993, pp. 58 s., quien, en el sentido de RADBRUCH, entiende el Derecho como obra de la cultura (el Derecho no se ha de equiparar con la norma abstracta, sino que el Derecho es "un acto", "un acontecer real" entre las personas que requiere a aquella norma pero que no se identifica con esta).

${ }^{9}$ RADBRUCH, Vorschule der Rechtsphilosophie, $2^{\text {a }}$ ed., 1959, p. 23.

${ }^{10}$ RADBRUCH, Rechtsphilosophie, 2003, § 2, p. 13.

11 "Natur der Sache ist die Lösung aller derer, welche den schroffen Dualismus von Sein und Sollen, von Wirklichkeit und Wert zu mildern bemüht sind, welche die Vernunft in den Dingen suchen”, RADBRUCH, Die Natur der Sache als juristische Denkform, 1964, p. 5.

${ }^{12}$ RADBRUCH, Vorschule der Rechtsphilosophie, $2^{\text {a }}$ ed., 1959, p. 23.

${ }^{13}$ Cfr. al respecto WAPLER, «Wertrelativismus und Positivismus. Theoretische Grundlagen der Rechts- und Staatsphilosophie Gustav Radbruchs» en PAULY (ed.), Rechts- und Staatsphilosophie des Relativismus. Pluralismus, Demokratie und Rechtsgeltung bei Gustav Radbruch, 2011, p. 37.
} 
las leyes de valoración (Wertgesetze) en el que se determina la corrección de la conducta. ${ }^{14}$ Ahora bien, cuando afirma que la naturaleza de las cosas pone límites al deber ser, la primera pregunta ineludible reza: ¿en qué medida pierde el deber ser su autonomía? Nótese que en RADBRUCH las valoraciones dejan de ser una pura construcción apriorística y se convierten en un complejo "ir y venir" del Derecho a su materia y de esta última al Derecho. La pieza clave es, pues, el significado de esa naturaleza de las cosas. Para RADBRUCH, en la medida en que la idea de Derecho se basa en la naturaleza del hombre, cuya esencia es la razón, tal naturaleza es puramente formal $\mathrm{y}$, por consiguiente, solo capaz de generar ciertas reglas ("lo que no quieras que te hagan no se lo hagas a los otros"), ${ }^{15}$ pero no un ordenamiento jurídico completo. ${ }^{16}$ Por ello, el Derecho debe dirigir su atención a su materia, a saber, los "estados naturales, sociales y jurídicos" previos al Derecho: la convivencia de los hombres, los modos de vida (Lebensverhältnisse) y órdenes de vida (Lebensordnungen) dentro de la sociedad. ${ }^{17}$ Por tanto, como materia del Derecho no son relevantes los hechos naturales o sociales considerados en sí mismos (rein naturale Rohsstoffe), ${ }^{18}$ sino en cuanto precursores sociales de las relaciones jurídicas (soziale Vorformen der Rechtsverhältnisse $)^{19}$ - por ej., formas de negocio, agrupaciones de personas con pretensión de ser reconocidas, conductas antisociales rechazadas por la conciencia del pueblo, la cual exige su prohibición y castigo-, formas que, en caso de cristalizar en Derecho consuetudinario, llegan a constituir un estado jurídico preexistente ${ }^{20}$ : lo vinculante para el Derecho no es la naturaleza ontológica de la materia, la naturaleza como algo que es (im Sinne eines Seienden) ${ }^{21}$, sino la naturaleza de la materia en cuanto esencia fruto de la atribución de un valor. Esto tiene pleno sentido si se tiene en cuenta que RADBRUCH, como neokantiano, parte del subjetivismo epistemológico (los valores no "son" sino que “son puestos" por el sujeto cognoscente) ${ }^{22}$, por lo que la esencia de las cosas no es una realidad ontológica objeto del conocimiento, sino una atribución. La naturaleza de las cosas es, pues, "el sentido de las cosas, el sentido objetivo que se desprende de la configuración de los modos de vida", es la respuesta a la pregunta: "cómo puede esta forma de vida (...) ser pensada como realización de una determinada idea de valor". ${ }^{23}$ Pues bien, el Derecho correcto es el que toma en consideración esa naturaleza de las cosas, ese valor fruto de una atribución, y ello por tres razones: (i) primero, por razones prácticas, esto es, para lograr la aplicación del Derecho a la realidad; un Derecho que ignore tal naturaleza de las cosas topará necesariamente con la resistencia de la materia -der Wiederstand der stumpfen Welt! -); (ii) segundo, porque el pensamiento jurídico se nutre del clima histórico en el que se forma; en

\footnotetext{
${ }^{14}$ RADBRUCH, Vorschule der Rechtsphilosophie, $2^{\mathrm{a}}$ ed., 1959, pp. 19 s.

${ }^{15}$ ENGISCH, «Gustav Radbruch als Rechtsphilosoph», en KAUFMANN, Arthur (ed.), Gedächtnisschrift für Gustav Radbruch, 21.11.1878-23.11.1949, 1968, p. 65.

${ }^{16}$ RADBRUCH, Vorschule der Rechtsphilosophie, $2^{\text {a }}$ ed., 1959, p. 20. En ello se vislumbra, pues, el rechazo de una visión del Derecho (no de la "idea de Derecho") absolutamente apriorístico.

${ }^{17}$ RADBRUCH, Die Natur der Sache als juristische Denkform, 1964, p. 10: “das Zusammenleben der Menschen, die Gesamtheit der Lebensverhätlnisse und Lebensordnungen innerhalb der Gesellschaft sowie die Lebenstatsachen, welche Bestandteile jener Verhältnisse und Ordnungen sind“.

${ }^{18}$ RADBRUCH, Die Natur der Sache als juristische Denkform, 1964, p. 11.

${ }^{19}$ RADBRUCH, Die Natur der Sache als juristische Denkform, 1964, p. 11.

20 RADBRUCH, Die Natur der Sache als juristische Denkform, 1964, p. 12; RADBRuCH, Vorschule der Rechtsphilosophie, $2^{\text {a }}$ ed., 1959, pp. 21 s.

${ }^{21}$ RADBRUCH, Die Natur der Sache als juristische Denkform, 1964, p. 13.

${ }^{22}$ SiLVA SÁncheZ, Aproximación al Derecho penal contemporáneo, $2^{\text {a }}$ ed., 2010, III.2.c.

${ }^{23}$ RADBRuCH, Die Natur der Sache als juristische Denkform, 1964, p. 13 (la cursiva es mía); EL MISMO, Vorschule der Rechtsphilosophie, p. 22.
} 
efecto, sea o no consciente de ello, dicho pensamiento se queda encerrado en los límites de lo históricamente posible; ${ }^{24}$ (iii) pero la razón primordial es, en tercer lugar, que "la validez de la naturaleza de las cosas está (...) fundamentada (...) por la misma esencia de la idea de Derecho”. ${ }^{25}$ La idea de Derecho está definida para una determinada materia y, consiguientemente, "también definida por dicha materia”. ${ }^{26}$ Esta compleja relación entre Derecho y materia, que en su día Roxin calificó como "interrelación” (Wechselbeziehung) entre ser y deber ser, entre materia (Stoff) y forma, ${ }^{27}$ la explica RADBRUCH recurriendo a una metáfora de LASK: naturaleza de las cosas es para la idea de Derecho como el material (mármol, bronce) para el artista. Del mismo modo, las ideas del Derecho están esencialmente determinadas "por la materia del Derecho, por la correspondiente ética, por el espíritu concreto del pueblo, en definitiva: por la naturaleza de las cosas". ${ }^{28}$ Así, la naturaleza de las cosas exige al Derecho que este configure la materia "con sentido". ${ }^{29}$

Así las cosas, ¿qué consecuencias tiene esta concepción en la relación entre Derecho, valor y realidad? ¿En qué medida es compatible la afirmación de que la naturaleza de las cosas, su sentido objetivo, no es el sentido "pensado por alguien", ${ }^{30}$ con la afirmación de que la naturaleza de las cosas no es un valor objetivo ontológicamente dado, sino fruto de una atribución? ¿Cuál es el verdadero límite que el ser le impone al deber ser? Aquí se muestra con toda su fuerza la tensión presente en la concepción de RADBRUCH: su método no es inductivo, no consiste en extraer el deber ser del $\operatorname{ser}^{31}$ (por imposibilidad lógica de deducir el valor de la realidad) ${ }^{32}$; pero tampoco es un método deductivo. Parecería que RADBRUCH pretende superar el puro subjetivismo epistemológico (el valor lo pone el sujeto cognoscente) y entrar en un plano superior al individuo, un plano intersubjetivo-social en el que tiene lugar una discusión sobre los valores y, con ello, sobre la propia identidad (sobre las formas de vida social vigentes). De lo contrario, no quedaría más remedio que ver en esa interacción entre Derecho y naturaleza de las cosas una pura circularidad en la que el Derecho pone el valor que después le limita. ${ }^{33}$

En efecto, la dinámica de retroalimentación entre naturaleza de las cosas e idea de Derecho genera la duda de si el planteamiento de RADBRUCH peca de circular, pues la naturaleza de las cosas limita al Derecho, pero esta última se determina a partir de la búsqueda de su sentido

\footnotetext{
${ }^{24}$ RADBRUCH, Vorschule der Rechtsphilosophie, $2^{\mathrm{a}}$ ed., 1959, p. 22.

${ }^{25}$ RADBRUCH, Vorschule der Rechtsphilosophie, $2^{\text {a }}$ ed., 1959, p. 23 (la cursiva es mía).

${ }^{26}$ RADBRUCH, Vorschule der Rechtsphilosophie, $2^{\text {a }}$ ed., 1959, p. 23, resaltado en el original; EL MISMO, Rechtsphilosophie, 2003, § 2, p. 14.

${ }^{27}$ Roxin, «Einige Bemerkungen zum Verhältnis von Rechtsidee und Rechtsstoff in der Systematik unseres Strafrechts», en KAUFMANN, Arthur (ed.), Gedächtnisschrift für Gustav Radbruch, 21.11.1878-23.11.1949, 1968, p. 261.

${ }^{28}$ RADBRUCH, Vorschule der Rechtsphilosophie, $2^{\text {a }}$ ed., 1959, p. 23.

${ }^{29}$ RADBRUCH, Die Natur der Sache als juristische Denkform, 1964, p. 15.

${ }^{30}$ RADBRUCH, Die Natur der Sache als juristische Denkform, 1964, p. 12.

31 "Sollensätze sind nur durch andere Sollensätze begründbar und beweisbar" (RADBRUCH, Rechtsphilosophie, 2003, § 2, núm. 2, p. 15).

${ }^{32}$ RADBRUCH, Rechtsphilosophie, 2003, § 2, núm. 1, pp. 14 s.

${ }^{33}$ Una circularidad que, por otra parte, es un problema esencial en la argumentación jurídica: cfr. al respecto el análisis de Arthur KAUFMANN, «Über den Zirkelschluss in der Rechtsfindung», en EL MISMO, Beiträge zur juristischen Hermeneutik sowie weitere rechtsphilosophische Abhandlungen, 2a ed., 1993, pp. 65 s.
} 
jurídico, de "cómo se realiza en esas cosas la idea de Derecho". ${ }^{34}$ Así, podría parecer circular afirmar que el sentido de la realidad que interesa al Derecho es un sentido "atribuido" a partir de la idea de Derecho ${ }^{35} \mathrm{y}$, a la vez, que el Derecho está determinado por la materia porque está definido para la materia. ${ }^{36} \mathrm{Y}$ es que, como dijo en su momento ENGISCH, "en cierta medida, con la naturaleza de las cosas, sacamos de la cosa tanto sentido objetivo como ha sido puesto previamente" en ella. ${ }^{37}$ ¿Es eso realmente así? Ciertamente, hay que aclarar si RADBRUCH pone las bases para salir de dicha circularidad o si su método tiene anclajes que permitan negarla. Nótese el carácter esencial de esta cuestión, pues si la sospecha de ENGISCH se confirma, el planteamiento de RADBRUCH, a saber, la "limitación" del deber ser por parte de la naturaleza de las cosas, sería una ficción de conexión del deber ser con el ser, ya que, en realidad, el deber ser estaría decidiendo de antemano lo que es la naturaleza de las cosas (la naturaleza de las cosas sería de facto algo apriorístico), es decir, decidiendo sobre sus propios límites, lo cual equivale a no tenerlos, esto es, a quedarse de facto en el dualismo metodológico. Y para este viaje no habrían hecho falta alforjas.

Pues bien, lo cierto es que, pese a negar el carácter ontológico de la naturaleza de las cosas, RADBRUCH sí parece entender dicha naturaleza como una atribución condicionada por el ser. Así, en lo que alcanzo, aunque la naturaleza de las cosas sea un juicio de atribución de una esencia, de un sentido objetivo desde la idea de Derecho, la materia acotaría la libertad de dicha atribución: por una parte, porque hay sentidos objetivos que la materia no tolera -continuando con la metáfora de LASK: el agua no tolera ser esculpida-y, por otra, porque hace que el juicio sea concebido ya para dicha materia. De lo contrario, no tiene sentido que RADBRUCH hable de un ir y venir del deber ser al ser y viceversa. Así pues, su planteamiento apuntaría a que el sustrato social condiciona el contenido del Derecho, derivando pues en un relativismo valorativo cuyo referente vinculante serían las formas sociales, los precursores de las relaciones jurídicas. Con todo, será necesario analizar la compatibilidad de esta interpretación de RADBRUCH con su subjetivismo epistemológico y su relativismo.

\subsection{La idea de Derecho}

Ahora bien, ¿cuál es esa idea de Derecho con la que interacciona la naturaleza de las cosas? Esta cuestión es esencial para el problema de la determinación del Derecho correcto. ${ }^{38}$ La idea de

\footnotetext{
${ }^{34}$ RADBRUCH, Die Natur der Sache als juristische Denkform, 1964, p. 13: "Natur der Sache ist ihr Wesen, ihr Sinn, und zwar nicht ein von irgend jemandem wirklich gedachter, vielmehr der allein aus der Beschaffenheit der Lebensverhältnisse selbst zu entnehmende objektive Sinn, die Antwort auf die Frage: wie kann dieses so beschaffene Lebensverhältnis als sinnvoll gedacht werden, d.h. als Verwirklichung einer Idee - und welcher Idee? Und zwar wird gesucht der juristische Sinn und die Rechtsidee, die sich in ihm verwirklicht“.

${ }^{35}$ En la línea de LASK, en quien RADBRUCH se inspira expresamente: "Ein jedes Sollen ist für einen bestimmten Stoff und deshalb auch durch diesen Stoff bestimmt” (citado por RADBRUCH, Die Natur der Sache als juristische Denkform, 1964, p. 16).

${ }^{36}$ RADBRUCH, Rechtsphilosophie, 2003, § 2, núm. 1, p. 14.

${ }^{37}$ ENGISCH, GS-Radbruch, p. 66. En este lugar conviene recordar la consideración de NeUmANN, «Neue Entwicklungen im Bereich der Argumentationsmuster zur Begründung oder zum Ausschluss strafrechtlicher Verantwortlichkeit», ZStW, (4), 1987, pp. 568 ss., quien entiende que aquella normativización que no introduzca teleológicamente contenidos materiales en la teoría del delito cae en una tautología.

${ }^{38}$ Este problema se reaviva con la aparición de la famosa fórmula de RADBRUCH. Cfr. al respecto PASTOR MuÑOZ, «Was bleibt übrig von dem Gesetzlichkeitsprinzip in dem Völkerstrafrecht? Zugleich ein Beitrag
} 
Derecho de RADBRUCH, inspirada por el neokantismo de STAMMLER, ${ }^{39}$ se basa en tres pilares: la justicia, la adecuación al fin (Zweckmäßigkeit) y la seguridad jurídica. La justicia es un valor absoluto, ${ }^{40}$ es el fin del Derecho ("Recht ist die Wirklichkeit, die den Sinn hat, der Gerechtigkeit zu dienen"). ${ }^{41}$ Pero dicha justicia es solo un valor formal, cuyo contenido esencial es la igualdad concebida en términos no ontológicos; así, la justicia obliga a tratar igual lo que es igual pero no determina qué debe ser considerado igual a qué. ${ }^{42}$ Dentro de la idea de justicia existe ya una primera tensión: la tensión entre la justicia general (Gerechtigkeit) y la pretensión de ofrecer una solución justa para el caso concreto (Billigkeit), ${ }^{43}$ una más de las muchas tensiones (no necesariamente negativas) a las que está sometida toda la concepción de RADBRUCH entre lo abstracto y lo concreto, lo deductivo y lo inductivo, el sistema y el caso. Inspirándose en la Ética a Nicómaco aristotélica, RADBRUCH considera que la Billigkeit es una forma de Gerechtigkeit y, con ello, sostiene que la una y la otra son solamente dos caminos para llegar al mismo lugar. Al igual que ocurre con la "naturaleza de las cosas" en la idea de Derecho, en la justicia opera la determinación de la idea por la materia (Stoffbestimmtheit der Idee): tenemos -así RADBRUCHque averiguar de qué clase es esa "realidad que está determinada a servir a la justicia” y "podemos extraer del sentido de la realidad conclusiones en cuanto a su esencia”. Obviamente, ello es esencial para aclarar qué exigencias dirige la justicia, en cuanto elemento de la idea de Derecho, al ordenamiento jurídico, en la medida en que el Derecho es una realidad (en la medida en que tiene positividad) que tiene el sentido de servir a la "idea de Derecho" (y en esa medida tiene normatividad, es valoración). ${ }^{44}$

La concepción formal de la justicia implica que haya pocos enunciados jurídicos que deriven directamente de ella (sí, el derecho a la defensa o la independencia del juez), proviniendo la mayoría de ellos de la idea de Zweckmässigkeit, la "adecuación al fin”. Este último fin (Zweck) no es el que defina un legislador positivo determinado, sino que se encuentra en el deber ser y proviene de la ética. Ahora bien, para RADBRUCH la ética no impone una jerarquía de valores inmutable, sino que el orden de los tres niveles de bienes éticos (libertad, comunidad, cultura, vinculados a los planos social, global y comunitario) depende de los pueblos, de los tiempos y de cada persona. ${ }^{45}$

über die Leistungsfähigkeit der Radbruchschen Formel», ARSP, (4), 2018, pp. 455 ss., con más referencias. Últimamente, NEUMANN, JZ, (1), 2020, pp. 7 ss.

39 VON DER PFORDTEN, «Die Rechtsidee bei Kant, Hegel, Stammler, Radbruch und Kaufmann», en SHING-I-LiU (ed.), Value, Pluralism, Tolerance and Law, 2002, pp. 1 s., 17 ss.

${ }^{40}$ Téngase en cuenta que la concepción de la justicia de RADBRUCH experimenta, como tantos otros aspectos de su pensamiento, cambios importantes: así, en los inicios (antes de 1914) RADBRUCH deduce la idea de justicia del valor ético del bien; en cambio, en la Rechtsphilosophie concibe la justicia como valor más elevado, no deductible, junto al valor de la verdad, el bien y la belleza, que está "al servicio del valor ético del bien” (WAPLER, en PAUly (ed.), Rechts- und Staatsphilosophie des Relativismus. Pluralismus, Demokratie und Rechtsgeltung bei Gustav Radbruch, 2011, p. 39).

${ }^{41}$ RADBRUCH, Rechtsphilosophie, 2003, § 4, núm. 1, p. 37.

${ }^{42}$ RADBRUCH, Rechtsphilosophie, 2003, § 4, núm. 1, pp. 35 s.; EL MISMO, Vorschule der Rechtsphilosophie, $2^{\mathrm{a}}$ ed., 1959, pp. 24 ss.

${ }^{43}$ RADBRUCH, Vorschule der Rechtsphilosophie, $2^{\text {a }}$ ed., 1959, p. 25.

${ }^{44}$ RADBRUCH, Rechtsphilosophie, 2003, § 4, núm. 1, pp. 37 s.: „Wie schließlich das Wesen der Gerechtigkeit ist, dieses Verhältnis [der Menschen untereinander] im Sinne der Gleichheit zu gestalten, so gehört es zum Wesen der rechtlichen Anordnung, ihrem Sinne nach auf Gleichheit gerichtet zu sein, den Anspruch der Generalisierbarkeit zu machen, generellen Charakter an sich zu tragen." (p. 38)

${ }^{45}$ En efecto, RADBRUCH entiende que la teoría ética de los bienes abarca tres niveles entre los que no existe una jerarquía: en el plano de la sociedad el referente es el sistema de valores individualista y el bien, la 
Ahora bien, de nuevo aquí hay que preguntarse si RADBRUCH limita de alguna manera el relativismo ético, es decir, si su idea de Derecho (y, en concreto, la Zweckmässigkeit) es una "caja vacía" susceptible de ser "rellenada" con cualquier sistema de valores (individualista, supraindividualista o transpersonalista) o si, en cambio, existen límites materiales. Y ya en este punto ( en el deber ser!) empieza a asomar algo que podría considerarse un elemento de norelativismo: en concreto, RADBRUCH, al vincular la Zweckmässigkeit con la teoría ética del deber, afirma que los deberes morales son exigencias absolutas al Derecho, el cual ha de garantizar "la posibilidad del cumplimiento del deber ético (...) aquel grado de libertad externa sin el cual no puede existir la libertad interna de la decisión ética". Aquí se constata, en lo que alcanzo, un primer límite al relativismo valorativo en la definición de la jerarquía de los bienes: "la negación absoluta de los derechos humanos o bien desde el punto de vista supraindividualista ("tú no eres nada, tu pueblo lo es todo") o desde un punto de vista transpersonalista ("una estatua de Fidias elimina toda la miseria de los millones de esclavos de la antigüedad”, TREITSCHKE)... es Derecho absolutamente incorrecto" ${ }^{46}$ Nótese que la exigencia, proveniente del deber ser, conforme a la cual el Derecho debe posibilitar el cumplimiento del deber ético y, para ello, garantizar un cierto grado de libertad externa, constituye un límite material para la definición del Derecho correcto. Ahora bien, la doctrina sigue discutiendo hoy sobre si ese límite al Derecho positivo se ancla en la teoría ética del deber y, por ello, RADBRUCH ya admitía, antes de su fórmula límites materiales al Derecho positivo que le permitían considerar incorrecto el Derecho del nacionalsocialismo, por acentuar este hasta el extremo la idea supraindividualista y negar los derechos humanos, ${ }^{47} \mathrm{O}$ si la afirmación de límites materiales se debe a un giro hacia el iusnaturalismo que se produce solo a partir de su "fórmula". ${ }^{8}$

Por último, la tercera columna de la idea de Derecho es la seguridad jurídica. Esta exige "positividad" e incluso la consolidación de situaciones "injustas" (la cosa juzgada, la prescripción, la consolidación como costumbre de un uso originariamente contrario a la ley). ${ }^{49}$ Así las cosas, las tensiones que pueden surgir en el seno de la idea de Derecho de RADBRUCH son evidentes: así, una visión supraindividualista como fin difícilmente es compatible con la justicia, y tampoco son compatibles seguridad jurídica y justicia cuando el Derecho positivo es injusto. Respecto a este último problema, RADBRUCH considera que la renuncia a la seguridad jurídica dependerá del "grado" de alejamiento del Derecho positivo de la idea de justicia, ${ }^{50}$ una solución que después consolidará en su conocida "fórmula". ${ }^{51}$

\subsection{El relativismo valorativo en Radbruch}

En la medida en que RADBRUCH introduce el valor en el Derecho y concibe el valor como una realidad subjetiva, es preciso preguntarse por el alcance de su relativismo valorativo:52

libertad; en el plano de la globalidad (Gesamtheit) el referente es el sistema de deberes supraindividualista y el bien, el poder; en el plano de la comunidad (Gemeinschaft), el sistema de valores es transpersonalista y el bien, la cultura.

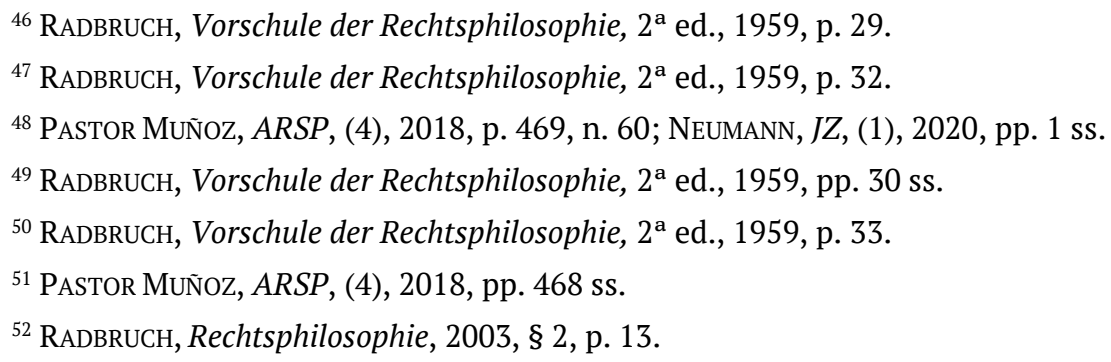


¿pertenece el valor al plano puramente subjetivo?; ¿es posible, al menos, alcanzar una cierta "intersubjetividad" de los valores - sin por ello afirmar su existencia objetiva-?, ¿o es posible incluso admitir valores objetivos indiscutibles? Desde la perspectiva del Derecho, es obvia la necesidad de poder afirmar que hay valores en cierta medida externos al sujeto cognoscente, pues si el único espacio de relevancia del valor es el sujeto, difícilmente puede hablarse de la entrada del valor en el Derecho. Cuando me refiero a valores "en cierta medida externos" lo hago en dos sentidos posibles: el primero, como valores de naturaleza subjetiva (puestos por el sujeto cognoscente) pero compartidos por los miembros de una sociedad y, en este sentido, intersubjetivos; en este primer sentido, podría afirmarse la existencia de valores sociales de contenido variable (dependientes de la configuración de la sociedad y, por ello, relativos), a los que se llegaría sacando el común denominador de las valoraciones subjetivas de los miembros de la sociedad. Pero también se puede hablar de valores externos en un segundo sentido, como valores con realidad objetiva con una existencia real independiente del sujeto cognoscente (valor como objeto del conocimiento, no como fruto de este). Ello implicaría entender que ni el sujeto cognoscente ni la sociedad tienen el poder absoluto de definir los valores, pues aquellos estarían limitados por la ontología (cuyo alcance se debería definir). Así las cosas, conviene examinar el relativismo de RADBRUCH a la luz de esta distinción.

En RADBRUCH, la apertura del Derecho a la naturaleza de las cosas no es concebida en el sentido de la apertura a un orden ontológico que es objeto del conocimiento, como sí lo hicieron diversos autores clásicos, partidarios de una concepción ontológica del valor (desde CICERÓN, ${ }^{53}$ Santo Tomás DE AQuino y el iusnaturalismo - la naturaleza de las cosas es la "ley intrínseca" a aquéllas - ${ }^{54}$ hasta DERNBURG - “die den Dingen innewohnende Ordnung”- ${ }^{55}$ o MONTESQUIEU ${ }^{56}$ ) y también autores que construyeron su concepción sobre la de RADBRUCH pero se distanciaron del relativismo valorativo (así Erik Wolf, que construye su concepción del valor desde la fenomenología de HuSSERL). ${ }^{57}$ Ahora bien, un planteamiento kantiano fuerte impide reconocer un valor objetivo - del ser no se puede extraer el deber ser, algo que, en cambio, sí podían hacer los monismos metodológicos: HEGEL, la escuela histórica, la interpretación materialista de la historia, el evolucionismo de Franz VON LISZT - ${ }^{58}$ ¿Es eso lo que ocurre también en el relativismo valorativo de RADBRUCH? ${ }^{59}$

\footnotetext{
${ }^{53}$ Recogida por JustinianO; citado por RADBRUCH, Die Natur der Sache als juristische Denkform, 1964, pp. 22, 24.

${ }^{54}$ Así MAUSBACH, Naturrecht und Völkerrecht, 1918, pp. 26 ss.: "Die menschlichen Handlungen erhalten ihre Regelung durch die Vernunftsnorm, die aus den geschaffenen Dingen hergeleitet wird”, citado por RADBRUCH, Die Natur der Sache als juristische Denkform, 1964, p. 6.

${ }_{55}$ Dernburg, Pandekten, v. I, 3a ed., 1892, p. 87, citado por RADBRuch, Die Natur der Sache als juristische Denkform, 1964, p. 8.

${ }^{56}$ Que en este punto se aproxima al iusnaturalismo de Hugo Grocio (MonsTESQUIEU, Esprit des lois, citado por RADBRUCH, Die Natur der Sache als juristische Denkform, 1964, p. 26).

${ }^{57}$ Este es el caso de Erik WOLF, que parte del método de RADBRUCH pero sustituye el relativismo valorativo de este último por la vinculación entre realidad y valor.

${ }^{58}$ ENGISCH, GS-Radbruch, p. 64.

${ }^{59}$ RADBRUCH, Rechtsphilosophie, 2003, § 2, p. 13.
} 
RADBRUCH concibe el valor como producto del sujeto cognoscente: ${ }^{60}$ "valor y desvalor provienen de nosotros, los observadores, no de las cosas y las personas mismas"; $; 1$ no podemos conocer lo que "es" valioso, sino lo que "es considerado" o "puede ser considerado" valioso. ${ }^{62}$ El valor, pues, no es un "hecho", sino un producto de la mente humana. ${ }^{63}$ Por ello, la corrección de un juicio de valor se puede determinar en relación con la máxima premisa valorativa (oberstes Werturteil), esto es, dentro de una determinada visión del mundo, del valor, pero no es posible afirmar o negar la corrección de dicha visión en sí. ${ }^{64}$ Así pues, tiene pleno sentido que la idea de justicia sea, en RADBRUCH, de carácter formal: en la medida en que la idea de Derecho tiene validez general, debe ser formal, por lo que el fin del Derecho es algo relativo y, por ello, no generalmente válido para la "idea de Derecho", sino solamente válido para la "obra humana" que es un determinado ordenamiento jurídico.

Si nos detuviéramos aquí, la conclusión a la que habría que llegar es que la referencia del Derecho al valor en el planteamiento de RADBRUCH no permite afirmar la existencia de valores externos al sujeto ni, por ello, tampoco someter al Derecho positivo a límites materiales: el fin del Derecho sería un valor relativo, objeto de una decisión y no de reconocimiento y, con ello, solo quedaría la posibilidad de afirmar la incorrección de un ordenamiento jurídico a la vista de ese valor/fin "decidido", pero no la posibilidad de juzgar a ese ordenamiento desde el deber ser (pues este es formal). A ello parece apuntar, por ejemplo, su trabajo sobre "Relativismo en la Filosofía del Derecho", en el que define el Derecho positivo como acto de autoridad, no de verdad; la decisión sobre los valores relevantes -afirma - es una decisión de la conciencia ${ }^{65}$ (y, en lo que alcanzo, no una imposición de la realidad). ¿Había que concluir, entonces, que en RADBRUCH el Derecho positivo puede incorporar cualquier valor? Esta cuestión es clave para determinar la relación entre valor y Derecho positivo, es decir, para dilucidar si el legislador está vinculado por los valores aceptados por la sociedad.

Desde luego, en primer lugar, la idea de justicia de RADBRUCH, por su carácter formal, no ofrece límites materiales. Ciertamente, este autor vincula justicia e igualdad, ${ }^{66}$ pero no dota a la idea de

\footnotetext{
${ }^{60}$ Cfr. con detalle, SiLva SÁNCHEZ, Aproximación al Derecho penal contemporáneo, $2^{\text {a }}$ ed., 2010, III.2.c.

${ }^{61}$ RADBRUCH, Rechtsphilosophie, 2003, § 1, p. 8.

62 ENGISCH, GS-Radbruch, p. 64.

${ }^{63}$ Wapler, en Pauly (ed.), Rechts- und Staatsphilosophie des Relativismus. Pluralismus, Demokratie und Rechtsgeltung bei Gustav Radbruch, 2011, p. 36.
}

${ }^{64}$ RADBRUCH, Rechtsphilosophie, 2003, § 2, núm. 2, p. 17: “Die hier dargelegte Methode nennt sich Relativismus, weil sie die Richtigkeit jedes Werturteils nur in Beziehung zu einem bestimmten obersten Werturteil, nur im Rahmen einer bestimmten Wert- und Weltanschauung, nicht aber die Richtigkeit dieses Werturteils, dieser Wertund Weltanschauung selbst festzustellen sich zur Aufgabe macht“. Dicho relativismo pertenece a la razón teórica, no a la razón práctica: por ello, implica un "Verzicht auf die wissenschaftliche Begründung letzter Stellungnahmen, nicht Verzicht auf die Stellungnahme selbst” p. 18. En este punto, RADBRUCH sigue a STAMMLER, quien en su "recuperación" del dualismo metodológico afirma claramente que el precio de la "validez general” de los conceptos de la Filosofía del Derecho es su carácter puramente formal, por lo que esta última no es capaz de generar enunciados jurídicos (RADBRUCH, Rechtsphilosophie, 2003, § 3, núm 8, p. 30, con referencias a STAMMLER en $\S 3$, núm. 7, p. 29). Ahora bien, nótese que RADBRUCH se distancia de STAMMLER en la medida en que "corrige" el dualismo metodológico, introduciendo la relación de valor entre el ser y el deber ser (Derecho como “wertbezogene Wirklichkeit, Kulturerscheinung”, § 3, núm. 9, p. 31).

${ }^{65}$ RADBRUCH, Der Mensch im Recht, 1957, pp. 82 ss.

66 WAPler, en Pauly (ed.), Rechts- und Staatsphilosophie des Relativismus. Pluralismus, Demokratie und Rechtsgeltung bei Gustav Radbruch, 2011, p. 49, atribuye gran importancia a este "límite" al relativismo de RADBRUCH, y la tiene en la medida en que permite negar que RADBRUCH sea "puramente positivista” (porque 
igualdad de un contenido material, por lo que bastaría que el legislador positivo defina como “distintas" dos clases de personas para poder tratarlas de manera diferente. En este sentido, el límite de la igualdad tiene una capacidad de rendimiento mínima, que se restringe a prohibir desigualdades internas en un Derecho positivo (esto es, el trato desigual de situaciones que la ley positiva considera iguales), pero no para medir el Derecho positivo conforme a criterios materiales externos.

En segundo lugar, hay un límite que no proviene de la teoría ética de los bienes, cuya jerarquía es relativa, sino de la teoría ética de los deberes (supra 2.3). Esta última obligaría, según RADBRUCH, a concebir el Derecho como posibilidad del cumplimiento moral de los deberes a través de la garantía de un grado suficiente de libertad externa. Y de ahí deduce el límite material que se encarna en los derechos humanos, ${ }^{67}$ en la figura del Estado de Derecho, ${ }^{68}$ un "contenido mínimo de Derecho natural" que todo Derecho positivo debe respetar para ser "Derecho correcto". ${ }^{69}$ Es más, llega a afirmar que el relativismo "exige" un Estado de Derecho (en definitiva, que el Estado esté sometido a la ley). ${ }^{70} \mathrm{Al}$ respecto, parece que RADBRUCH llega a conclusiones semejantes a las del iusnaturalismo de la Ilustración: el "relativismo exige un Estado de Derecho" (con sumisión del Estado a las leyes que genera) y el "Estado de Derecho no puede existir sin separación de poderes”. ${ }^{71}$ Pero ¿está admitiendo con ello un límite material absoluto al Derecho positivo y, por tanto, la necesidad de abandonar o, por lo menos, reducir el alcance de su concepción relativista del valor? ¿Es eso lo que acontece cuando rechaza la pena de muerte y las penas infamantes?, ${ }^{72}$ ¿o cuando rechaza las "leyes criminales" del nacionalsocialismo? ${ }^{73}$ El límite de los derechos humanos en RADBRUCH no es un límite iusnaturalista à la GROCIO (derechos humanos con contenido eterno). Tampoco se trata de un límite formulado desde la Filosofía de la Religión del Derecho (Religionsphilosphie des Rechts), la “wertüberwindende Betrachtung”, en la que se trata de

vincula Derecho e idea de Derecho y, con ello, permite diferenciar el “Derecho" del "No-Derecho"). Sin embargo (véase a continuación en el texto), hay que ser conscientes de que se trata de un límite muy débil. De hecho, la misma WAPLER añade que, en realidad, la "referencia a la justicia" que ha de tener el Derecho la cumpliría “cualquier regulación formulada en términos generales” (p. 49).

${ }^{67}$ RADBRUCH, Vorschule der Rechtsphilosophie, $2^{\text {a }}$ ed., 1959, p. 98.

${ }^{68}$ RADBRUCH, «Erneuerung des Rechts», en KAUfMANN, Arthur (ed.), Gedächtnisschrift für Gustav Radbruch, 21.11.1878-23.11.1949, 1968, pp. 26 s. Así lo interpreta ENGISCH, GS-Radbruch, p. 66, remitiéndose a una de sus últimas conversaciones con RADBRUCH, en la que este último subrayaba que Derecho y moral pertenecen al "deber ser", no al deber del "müssen", por lo que un ordenamiento coactivo (Zwangsordnung) sería "Naturordnung” y no "Rechtsordnung”. No es “Derecho" coaccionar a alguien a un comportamiento, sino el “deber”, cuyo cumplimiento procede de la libertad interna. Así pues, para que se produzca el cumplimiento libre del deber es preciso que el ordenamiento jurídico garantice la libertad externa necesaria para que pueda existir la libertad interna de la decisión moral (pp. 66 s.).

${ }^{69}$ ENGISCH, GS-Radbruch, p. 67.

${ }^{70}$ RADBRUCH, Der Mensch im Recht, 1957, p. 84: „Aber das positive Recht kann diese seine Sicherheitsaufgabe nur unter der Voraussetzung erfüllen, daß es nicht allein die Rechtsunterworfenen verpflichte, sondern auch den Gesetzgeber selbst. Es wäre um die Rechtssicherheits geschehen, wenn der Gesetzgeber in der Lage wäre nach Willkür Ausnahmen vom Gesetz zu machen. Die Gesetzgebung ist dem Gesetzgeber anvertraut nur unter der Bedingung, daß er sich selbst der Herrschaft des Gesetzes unterwerfe. Ein Staat, der sich seinem eigenen Gesetz unterworfen weiß, heißt nach der deutschen Rechtssprache Rechtsstaat. Der Relativismus fordert den Rechtsstaat“.

${ }^{71}$ RADBRUCH, Der Mensch im Recht, 1957, p. 84.

${ }^{72}$ RADBRUCH, Vorschule der Rechtsphilosophie, $2^{\text {a }}$ ed., 1959, p. 99.

${ }^{73}$ RadBruch, en KAUFMANN, Arthur (ed.), Gedächtnisschrift für Gustav Radbruch, 21.11.1878-23.11.1949, 1968, p. 26. 
juzgar al Derecho "ante Dios" o ante "la esencia más absoluta de las cosas"; $;{ }^{74}$ no lo es porque al "Derecho incorrecto" (leyes nacionalsocialistas) RADBRUCH le niega su "vigencia” y la "vigencia" no es un juicio "wertüberwindend", sino "bewertend" (esto es, de la Filosofía del Derecho). Pues bien, todo apunta a que el camino metodológico que emprende RADBRUCH para fundamentar determinados presupuestos absolutos (Estado de Derecho, separación de poderes, democracia) es precisamente el principio del relativismo (!). ${ }^{75} \mathrm{Y}$ es que sería un error interpretativo entender que para RADBRUCH todo es relativo; lo relativo son los valores recogidos en el Derecho positivo (que ve como acto de autoridad, no como acto de verdad). De ahí que entienda que el relativismo exige que el Derecho positivo tenga determinados rasgos. El mismo reconoce que, a través de un camino metodológico distinto al del Derecho natural, a saber, el relativismo, se llega a determinadas conclusiones absolutas sobre el Derecho justo. ${ }^{76}$ En conclusión, RADBRUCH intenta lograr un complejo equilibrio para no seguir ni el camino de WINDELBAND y RICKERT ni tampoco el de KeLSEN. Los primeros, neokantianos de la Escuela del Sur de Alemania, entendieron que una actitud que niegue la posibilidad de tomar una decisión definitiva sobre valores conduce a la "arbitrariedad en los contenidos" - algo que ocurriría cuando se considera que los enunciados últimos de valor no son fundamentables - y, por ello, rechazaron el relativismo y defendieron la existencia de valores supremos atemporales y con validez general. ${ }^{77}$ El segundo (KELSEN) optaría por quedarse con conceptos formales, renunciando a contenidos materiales inmutables. Ahora bien, ese equilibro de RADBRUCH es difícil: llegar por el relativismo a conclusiones absolutas.

Cierto es, en tercer lugar, que algún autor ha visto en la apelación de RADBRUCH a la conciencia como fuente del juicio de valor (el juicio de valor proviene de la conciencia, no de la arbitrariedad) un límite a la decisión sobre valores. Así, Werner GOLDSCHMIDT entiende que en RADBRUCH los enunciados últimos de valor no son fruto de un "conocimiento por creencia" (Bekenntnis: gläubiges Wissen), sino de un conocimiento axiomático no demostrable basado en experiencias de evidencia (nicht beweisbare, auf Evidenzerlebnisse stützende Erkenntnis). ${ }^{78}$ Si las cosas son así, las decisiones relativas al valor (los enunciados de valor últimos) no se formularían en condiciones de absoluta libertad, sino limitados por dichas "experiencias de lo evidente", aunque carecerían de la calidad de "conocimiento demostrable” y, en lo que alcanzo, serían subjetivas. Por consiguiente, podríamos aventurarnos a decir que en RADBRUCH el límite de la conciencia contendría el peligro de la arbitrariedad y sería, en cierta medida, una posible fuente de cierta generalización de los valores últimos. La experiencia "de lo evidente" de los miembros de una sociedad les conduciría a conclusiones de conciencia semejantes sobre cuáles son los valores últimos. De ahí surgiría un común denominador de valores últimos para esa sociedad (en lo que

\footnotetext{
${ }^{74}$ RADBRUCH, Rechtsphilosophie, 2003, § 1, pp. 11 s. Como subraya HAUSER, «Die verborgene Lebenslinie. Gustav Radbruch und die Religion», en KaUfMAnN, Arthur (ed.), Gedächtnisschrift für Gustav Radbruch, 21.11.1878-23.11.1949, 1968, pp. 51 s., el juicio de la Filosofía de la religión no es ni del “ser” ni del “deber ser”, sino que tiene que ver con recoger "esencia de las cosas” en conceptos.

75 NeUmann, JZ, (1), 2020, p. 7.

${ }^{76}$ RADBRUCH, Der Mensch im Recht, 1957, p. 85.

77 WaPler, en Pauly (ed.), Rechts- und Staatsphilosophie des Relativismus. Pluralismus, Demokratie und Rechtsgeltung bei Gustav Radbruch, 2011, p. 40.

${ }^{78}$ GoldschmidT, Werner, «Erkenntnis und Bekenntnis», en KAUFMANN, Arthur (ed.), Gedächtnisschrift für Gustav Radbruch, 21.11.1878-23.11.1949, 1968, pp. 95, 101 s.: “Die Rechtsphilosophie darf sich (...) nicht darauf beschränken, die verschiedenen Gerechtigkeitsregime symbolisiert und axiomatisiert dem Leser zur gefälligen Auswahl vorzulegen. Sie muß vielmehr selbst erklären, welches der Gerechtigkeitsregime sie für evident hält“ (el resaltado es mío).
} 
alcanzo, intersubjetivos, ¡no objetivos!). Al respecto, resultaría esencial seleccionar los verdaderos actos de conocimiento de los valores últimos de aquellos actos de conocimiento de valores aparentes, pues no toda expresión sobre los valores esenciales podría explicarse como conocimiento basado en experiencias de lo evidente; este criterio permitiría hacer una criba y seleccionar los verdaderos valores compartidos por una sociedad. Probablemente, la coincidencia de los diversos juicios de valor último se debería poner en relación con la naturaleza humana que todos compartimos, pero eso implicaría ir mucho más allá de la posición de RADBRUCH.

Lo que el planteamiento de RADBRUCH permite fundamentar es que las valoraciones individualizadas de los miembros de una sociedad cristalizan en la "naturaleza de las cosas" (los precursores de las relaciones jurídicas) y que esta última vincula al Derecho. La vigencia de valores depende de cada sociedad (die Auffassung einer Gesellschaft). ${ }^{79}$ Es decir, probablemente RADBRUCH no formularía ninguna objeción al paso del valor subjetivo al valor intersubjetivo, el juicio de valor compartido por una sociedad. Harina de otro costal es qué grado de vinculación existe entre valoraciones sociales (el sentido de las formas de vida social, la "naturaleza de las cosas”) y Derecho en cuanto obra de la cultura, es decir, en qué medida el Derecho positivo debe reflejar el "clima histórico" que está en la materia ${ }^{80}$ Por otra parte, surge la pregunta de cómo se determina la visión del mundo (no permanente, sino dependiente del tiempo y lugar, de la sociedad) que ha de tomar como referente el Derecho, es decir, cómo se definen los valores de una sociedad cuando esta es plural ${ }^{81}$ ("dentro de cada comunidad (...) no hay solamente una interpretación del valor, sino varias"), ${ }^{82}$ determinación que no se debe realizar mediante un proceso formal. ${ }^{83} \mathrm{Y}$ esta cuestión, sin duda, nos recuerda al problema epistemológico del normativismo en la determinación del "núcleo de la identidad normativa de la sociedad". Pero sea como fuere parece claro que RADBRUCH sí identifica un orden de valores externo al sujeto, en concreto, social, aunque de entrada lo considere no permanente, sino dependiente del Zeitgeist (intersubjetivo, no objetivo: compartido por los sujetos, pero sin realidad ontológica).

En cuarto lugar, hay que subrayar que RADBRUCH ubica el juicio valorativo sobre el Derecho positivo en la Filosofía del Derecho (bewertende Betrachtung), ${ }^{84}$ pero, en lo que alcanzo, la Filosofía del Derecho no juzgaría al Derecho positivo conforme a valores materiales - RADBRUCH parte del relativismo-, pues queda en el poder del legislador la elección de los valores legislación como acto de autoridad, no como acto de verdad-. ${ }^{85}$ Por tanto, la "corrección" del Derecho pertenece como idea a la razón pura y, por ello, goza de validez general, pero el

\footnotetext{
${ }^{79}$ RADBRUCH, Der Mensch im Recht, 1957, p. 81.

${ }^{80}$ Así lo entiende WÜRTENBERGER, «Zur Idee des „sozialen Rechts" bei Gustav Radbruch», en KaUfMANN, Arthur (ed.), Gedächtnisschrift für Gustav Radbruch, 21.11.1878-23.11.1949, 1968, pp. 202 s.

${ }^{81}$ SILVA SÁNCHEZ, Aproximación al Derecho penal contemporáneo, $2^{\mathrm{a}}$ ed., 2010, III.4.C.c.

82 RADBRUCH. Rechtsphilosophie, 2003, § 2, núm. 2, p. 19, n. 21, critica a KRIECK, Wissenschaft Weltanschauung, Hochschulreform, 1934.

${ }^{83}$ Algo que se percibe en la crítica de RADBRUCH a KELSEN, en la que aquel rechaza una idea puramente formal de democracia, pues considera inherente a la democracia el elemento de la libertad (como reconocimiento del Estado de Derecho, de la personalidad y de la creación de cultura), Vorschule der Rechtsphilosophie, $2^{\mathrm{a}}$ ed., 1959, p. 105.

${ }^{84}$ La Filosofía del Derecho y la Ética son pues las que contienen “doctrina material del valor” (materiale Wertlehre), cfr. ENGISCH, GS-Radbruch, pp. 63 s.

${ }^{85}$ RADBRUCH, Der Mensch im Recht, 1957, p. 81.
} 
contenido (conocimientos y valoraciones) pertenece a la razón práctica, por lo que solamente es válido para un determinado estado de la sociedad, para una época determinada y para un pueblo determinado. ${ }^{86}$ Así las cosas, tiene sentido que algunos autores se hayan planteado si la "fórmula de RADBRUCH" (Gesetzliches Unrecht und übergesetzliches Recht) modifica el modo en que concibe el juicio sobre la corrección del Derecho positivo, juicio que, a partir de la fórmula, se basaría en valores materiales permanentes y, por ello, conduciría a un iusnaturalismo de mínimos. En efecto, según esta interpretación, la fórmula de RADBRUCH fijaría una jerarquía entre los tres pilares de la idea de Derecho, pasando la justicia a estar por encima de la seguridad jurídica, ${ }^{87}$ e implicaría abandonar la afirmación de que "cualquier bien ético" (cualquier modelo de Estado: individualista, traspersonalista o supraindividualista) es admisible como fin del Derecho. ${ }^{88}$ Así NEUMANN ha entendido que la fórmula implica introducir un límite externo a la "libertad" del Derecho en sus decisiones valorativas ("ontologische Wendung") y que es dudoso que sea compatible con el paradigma metodológico de RADBRUCH conforme al cual el Derecho es una realidad referida al valor (wertbezogene Gegebenheit) que tiene el sentido de ser justa pero que puede ser justa o no serlo, y que, en caso de no serlo, sigue siendo Derecho. ${ }^{89} \mathrm{Si}$ ello es así o si, por el contrario, con su fórmula RADBRUCH solo intenta desarrollar los límites absolutos ya deducidos con anterioridad de su propio relativismo es una cuestión compleja.

Sea como fuere, este punto, hoy todavía importante, pone de relieve la dificultad (¿o imposibilidad?) metodológica del neokantismo para aceptar contenidos permanentes: en RADBRUCH dichos contenidos se reducirían, antes de su fórmula, a presupuestos necesarios para la posibilidad del relativismo. En ese punto, sí es posible construir el puente de la valoración individual subjetiva a la valoración social, pero esta no sería sino la generalización de un juicio de valor individual altamente compartido (es decir, el valor mantendría su naturaleza subjetiva y no permanente). El paso cualitativamente relevante es el consistente en admitir valores objetivos que limiten al cognoscente (o a la sociedad), algo que solo parece posible con la admisión de un iusnaturalismo de mínimos. Dicho sea de paso, eso no cierra el problema, pues el iusnaturalismo - como, por cierto, también el positivismo - tiene un problema metodológico de argumentación circular, ${ }^{90}$ el problema de presentar como conocimiento lo que en realidad son convicciones subjetivas.

\footnotetext{
${ }^{86}$ RADBRUCH, Rechtsphilosophie, 2003, § 3, núm. 1, p. 22.

${ }^{87}$ Cfr. el análisis de NeumanN, «Naturrecht und Positivismus im Denken Gustav Radbruchs. Kontinuitäten und Diskontinuitäten», en HÄrLE/Vogel (eds.), „Vom Rechte, das mit uns geboren ist“. Aktuelle Probleme des Naturrechts, 2007, pp. 11 ss.

88 Cfr. al respecto LEICHT, «Obrigkeitspositivismus und Widerstand», en KAUFMANN, Arthur (ed.), Gedächtnisschrift für Gustav Radbruch, 21.11.1878-23.11.1949, 1968, p. 194. Con detalle, PASTOR MuÑOZ, ARSP, (4), 2018, pp. 475 s.

${ }^{89}$ Es decir, RADBRUCH abandonaría la idea de que el Derecho está “referido al valor” (wertbezogen) pero no es “valoración” (bewertend) (NEUMANN, en HÄrLE/Vogel (eds.), „Vom Rechte, das mit uns geboren ist“. Aktuelle Probleme des Naturrechts, 2007, p. 18); vON DER PFORDTEN, en SHING-I-Liu (ed.), Value, Pluralism, Tolerance and Law, 2002, p. 3, que con razón afirma que en RADBRUCH la labor „bewertend“ pertenece a la "idea de Derecho", no al "concepto de Derecho”.

${ }^{90}$ KaUfMANn, Arthur, Beiträge zur juristischen Hermeneutik sowie weitere rechtsphilosophische Abhandlungen, $2^{\text {a }}$ ed., 1993, pp. 66 ss.
} 


\section{La impronta del método y del relativismo valorativo de Radbruch en una visión valorativa del Derecho penal}

Como indicaba antes, RADBRUCH "abre" el Derecho a la naturaleza de las cosas, a la materia que aquel debe regular. La naturaleza de las cosas ofrece resistencia, limita o incluso configura la idea de Derecho. ${ }^{91}$ Con ello, surge un puente entre ser y deber ser que supera el abismo cavado por el dualismo metodológico, ${ }^{92}$ pero que no debería malinterpretarse como monismo: ni la naturaleza de las cosas determina completamente la idea de Derecho ni a la inversa; ni hay una dictadura de la materia, ni hay una dictadura del deber ser. Dentro del espacio definido por la naturaleza de las cosas, el legislador goza de libertad para generar un ordenamiento jurídico más abstracto y, con ello, más resistente a los cambios de la vida económica y social o, en cambio, un ordenamiento jurídico más concreto, más vinculado a las formas de vida social y económica y, por ello, más "efímero". ${ }^{93}$ Pues bien, este enfoque metodológico tiene importantes consecuencias para el Derecho penal.

Así, si la naturaleza de las cosas, las formas de vida social, se entiende como una realidad autónoma que limita "desde fuera" a la idea de Derecho, al deber ser. Es decir, si partimos de que la categoría de la naturaleza de las cosas no es una paráfrasis del deber ser ni, con ello, un monismo encubierto, ello implica, en primer lugar, que el Derecho y, en lo que ahora interesa, el Derecho penal están vinculados por el sustrato social, el "sentido" de la vida social. Así, el Derecho penal no podría emitir juicios de desaprobación ignorando los juicios sociales de desaprobación preexistentes. Ciertamente, la validez jurídica del juicio de desaprobación proviene del Derecho, pero la decisión del legislador no puede ser arbitraria, pues ello contradiría la idea de Derecho. ${ }^{94}$ De ahí se derivan claros límites materiales (intersubjetivos, sociales) a la criminalización de conductas y un mandato de sintonía (no necesariamente identidad) entre valoración social y valoración jurídico-penal, algo que se plasma hoy en la defensa de un concepto material de delito (ROBLES PlanAS) ${ }^{95}$.

En segundo lugar, la visión de RADBRUCH de la relación entre el Derecho y su materia implica que la relación entre ambos no es unidireccional (ni apriorística, ni inductiva), sino que la construcción jurídica es un "ir y venir" del Derecho a la realidad y viceversa. Ese ir y venir lo concibe en los términos de RICKERT y WEBER (también neokantianos): hay que partir de las relaciones vitales y sus concretas reglas de conducta, interpretar su sentido a partir de la referencia a las ideas (extraer de las formas de vida su sentido objetivo) ${ }^{96}$ para llegar a un "tipo ideal" (Idealtypus) del instituto jurídico; a partir de este último, se deben desarrollar reglas jurídicas concretas - tanto las que han servido como punto de partida de todo el proceso, como

\footnotetext{
${ }^{91}$ RADBRUCH, Die Natur der Sache als juristische Denkform, 1964, p. 15.

92 BARATTA, «Valores y método jurídico en el positivismo penal alemán», en CHIAPPINI, Problemas de Derecho penal, 1983, pp. $241 \mathrm{~s}$.

${ }^{93}$ RADBRUCH, Vorschule der Rechtsphilosophie, $2^{\text {a }}$ ed., 1959, p. 84.

${ }^{94}$ RADBRuCH, Die Natur der Sache als juristische Denkform, 1964, p. 15: „Rechtsidee“ como „Leitgedanke“ del legislador.

95 Robles Planas, «Dogmática de los límites al Derecho penal», en VON HiRSCH/SEelMANN/Wholers (ed. alemana)/RoBles Planas (ed. española), Límites al Derecho penal. Principios operativos en la fundamentación del castigo, 2012, pp. 19 ss.; EL MISMO, «Normas de conducta», InDret, (1), 2019, pp. 7 ss.; EL MISMO, «La identidad de la dogmática jurídico-penal», ZIS, (2), 2010, pp. 140 ss.
}

${ }^{96}$ RADBRUCH, Die Natur der Sache als juristische Denkform, 1964, p. 13. 
nuevas reglas que se derivan como consecuencia lógica de la esencia del instituto jurídico- ${ }^{97}$ Ello implica, por una parte, el rechazo de un sistema dogmático cerrado, que vive de espaldas a la realidad y pretende tener validez al margen de esta última -radical separación entre el mundo del Derecho y la realidad, como la concibió la escuela histórica del Derecho de SAVIGNY ${ }^{98}$-, pero también, por otra, la defensa de la dogmática sistemática y la superación del pensamiento tópico. Ese rechazo de una dogmática hermética y la defensa del pensamiento sistemático ${ }^{99}$ son elementos que adoptará después Roxin y que permanecerán en la visión normativista del sistema del delito.

Además, es esencial subrayar, en tercer lugar, que el pensamiento de RADBRUCH deja otra impronta importante en la dogmática-jurídico penal, a saber, la entrada del valor en la dogmática. Ello tiene sus luces y sus sombras: con la entrada del valor se logra una concepción del Derecho más satisfactoria, pero llegan también los problemas vinculados a la definición del valor y el acceso epistemológico a este y, en concreto, el problema del relativismo valorativo. Ciertamente, la incorporación del valor al sistema jurídico y la generación, con ello, de una teoría teleológica, no es una aportación exclusiva de RADBRUCH: aquella ya aparece claramente en IHERING, cuya influencia en RADBRUCH es perceptible. Pero sí puede decirse que los neokantianos -y probablemente RADBRUCH y la Escuela Sudoccidental con mayor fuerza- contribuyeron con especial intensidad a la superación del positivismo, a la introducción del valor en la dogmática. Que la dogmática jurídico-penal no es, no puede ser, positivista, si es que quiere ser algo más que filología de la ley, está claro. Y esa apertura de la dogmática al valor ser ve claramente en Roxin, ${ }^{100}$ cuya visión entronca de hecho con el neokantismo (el finalismo, desde este punto de vista, sería, con palabras de SILVA SÁNCHEZ, un paréntesis metodológico, ${ }^{101}$ un periodo en el que se volvió al sistema cerrado). Ahora bien, con la entrada del valor en la dogmática, la tarea de esta última se vuelve mucho más compleja y ambiciosa: ya no se trata de describir, sino de imputar, y los criterios de imputación requieren una fundamentación basada en argumentos basados en valores, no en hechos físico-naturales. Esa es la gran aportación (y, a la vez, la cruz) del normativismo: hay que discutir sobre la naturaleza del valor.

En cuarto lugar, en lo que atañe al valor, el relativismo valorativo de RADBRUCH -cuyo alcance ha sido antes objeto de análisis- determina que el sistema jurídico y, en concreto, el Derecho penal resista al paso del tiempo, en la medida en que puede ser dotado de diferentes contenidos valorativos dependientes de la configuración histórico-cultural de la sociedad para la que dicho

\footnotetext{
${ }^{97}$ RADBRUCH, Die Natur der Sache als juristische Denkform, 1964, p. 14.

98 RADBRUCH, Vorschule der Rechtsphilosophie, $2^{\mathrm{a}}$ ed., 1959, p. 74. SAVIGNY y su Escuela proponían una interpretación "jurídico-conceptual" alejada de toda necesidad del presente. Esto -junto al "formalismo romántico" de dicha escuela, que pretende que el juez sea, siguiendo a MonTESQUiEU, la mera boca que pronuncia las palabras de la ley, sin realizar valoración alguna - forma parte de las razones de la crítica de RADBRUCH a dicha concepción de la ciencia del Derecho.

${ }^{99}$ Conviene recordar aquí la discusión que genera la obra de Roxin de 1970 Política criminal y sistema del Derecho penal y su influencia enorme en la ciencia penal posterior. A partir de ahí, también entre nosotros se recoge de formas diversas esa visión del sistema del Derecho penal como un sistema propio, no esclavo del caso, capaz de pensamiento sistemático, pero a la vez capaz absorber los problemas que plantea la realidad.

${ }^{100}$ Cfr. el análisis detallado de SILVA SÁNCHEZ, «Política criminal en la dogmática: algunas cuestiones sobre su contenido y límites», en EL MISMo (ed.), Política criminal y nuevo Derecho penal. Libro Homenaje a Claus Roxin, 1997, pp. 18 ss.

${ }^{101}$ SILVA SÁNCHEZ, Aproximación al Derecho penal contemporáneo, $2^{\mathrm{a}}$ ed., 2010, II.2.D.
} 
Derecho nace. En definitiva, un cierto relativismo hace posible que el Derecho penal tenga una dimensión histórica, cambiante. En ese punto, de nuevo, RADBRUCH busca un equilibrio entre lo apriorístico y la naturaleza de las cosas: el concepto de Derecho es apriorístico, al igual que una serie de conceptos jurídicos (enunciado jurídico y sus partes -tipo y consecuencia jurídica-; fuente del Derecho u origen de la normatividad, conformidad y contrariedad a Derecho; derechos y deberes jurídicos como modo de regular las relaciones jurídicas; sujetos de Derecho y objetos de Derecho) ${ }^{102}$, de ahí la dimensión sistemática del Derecho. Ahora bien, al estar este último abierto a la naturaleza de las cosas, a la realidad cambiante, se incorpora una dimensión que también es cambiante: "El ideal del Derecho es un ideal precisamente para el Derecho y, además, para el Derecho de una época determinada, un pueblo determinado, unas relaciones sociológicas e históricas muy concretas". ${ }^{103}$ Con ello, incorpora al ordenamiento jurídico (a la realización del concepto de Derecho) lo "pasajero", mutable, aunque imprescindible, ${ }^{104}$ es decir, lo contingente ${ }^{105} \mathrm{y}$ descarta una visión hermética el sistema. ${ }^{106}$ Ahora bien, la pregunta esencial es si lo permanente en RADBRUCH son determinados conceptos formales o también determinados valores, ${ }^{107}$ un problema al que me he referido antes (supra 2.4).

\section{La visión de Radbruch de teoría del delito y la dogmática jurídico-penal}

\subsection{La naturaleza de las cosas en la construcción de la teoría del delito}

La breve aproximación a cómo concibe RADBRUCH el método debería haber servido para subrayar el carácter central de la naturaleza de las cosas como forma de pensamiento jurídico, una concepción de la construcción jurídica que no opta ni por construir conceptos puramente

\footnotetext{
102 RADBRUCH, Rechtsphilosophie, 2003, § 4, p. 39. Dicho elenco de conceptos jurídicos apriorísticos no es cerrado: la aprioridad es un concepto relacional (entre conceptos y un material fáctico), por lo que no puede ser acotada previamente.

${ }^{103}$ RADBRUCH, Rechsphilosophie, 2003, § 2, p. 13.

${ }^{104}$ De modo inequívoco en este pasaje: "Die Idee [des Rechts] gilt für einen bestimmten Stoff, ist auf diesen Stoff hingeordnet - und ist also von dem Stoff, den sie beherrschen will, wiederum mitbestimmt” (Rechsphilosophie, 2003, § 2, p. 13).

105 MARCIC, «Gustav Radbruch und Hans Kelsen», en KAUFMANN, Arthur (ed.), Gedächtnisschrift für Gustav Radbruch, 21.11.1878-23.11.1949, 1968, p. 84.

106 De ahí la ya mencionada crítica al iusnaturalismo, que pretende deducir de la ley divina el Derecho concreto, sin tener en cuenta el tiempo y lugar al que debe ser aplicado, pero también al dualismo metodológico estricto, que impide que el "ser” tenga relevancia alguna para el “deber ser”.

${ }^{107}$ Parece clara la distancia respecto a la doctrina de Tomás DE AQUINO. Ahora bien, téngase en cuenta que Tomás DE AQUINO reconocía abiertamente una dimensión histórica del Derecho, pues entendía que justicia significa dar a cada uno lo que le corresponde, pero la determinación de lo que es justo es necesariamente distinto según los distintos estados de la humanidad. Cfr. ScHWARZSCHILD, "Über Gerechtigkeit», en KaUfMANN, Arthur (ed.), Gedächtnisschrift für Gustav Radbruch, 21.11.1878-23.11.1949, 1968, p. 73. Al respecto, también VERDROSs, «Beständigkeit und Geschichtlichkeit im Recht», en KAUFMANN, Arthur (ed.), Gedächtnisschrift für Gustav Radbruch, 21.11.1878-23.11.1949, 1968, p. 136: por ello, en el planteamiento tomista, los principios de Derecho natural no pueden ser aplicados en todas partes del mismo modo (cfr. en pp. 136 s., con referencias a MESSNER y FUCHS).
} 
jurídicos ${ }^{108}$ ni se orienta según conceptos provenientes del ser. ${ }^{109}$ Según RADBRUCH, la teoría del delito no está vinculada por lo empírico, ${ }^{110}$ pero sí por el sentido objetivo que se debe atribuir a la realidad: dicho sentido objetivo que se desprende de la configuración de las formas de vida, es la respuesta a la pregunta "cómo este modo de vida, configurado de esta manera, puede ser pensado como realización de una determinada idea de valor". ${ }^{111}$ En lo que alcanzo, en primer lugar, el claro distanciamiento de RADBRUCH respecto a una visión de la construcción jurídica vinculada a los conceptos "empíricos" - por cierto, un abandono de planteamiento causalista todavía presente en su escrito de habilitación- y la introducción del "sentido objetivo" de la realidad como referente de la construcción del Derecho va vinculada a la concepción del delito como sentido y no como ontología, entroncando claramente con el sistema normativista del delito. En segundo lugar, en lo que concierne a la determinación del sentido objetivo de la realidad social, RADBRUCH considera que los conceptos de la teoría del delito no surgen de un consenso, de la “doctrina dominante", sino de la comprensión inevitable (zwingende Erkenntnis) de la naturaleza de las cosas, que está por encima de la doctrina dominante y por encima de las definiciones legales $^{112}$ (iy, con ello, del legislador!). ${ }^{113}$ Este modo de ver las cosas es el que hoy sostenemos quienes consideramos que la dogmática, el sistema de criterios para una adecuada imputación de responsabilidad penal, no es fruto de una "convención" (del juego de las mayorías, de una legitimación puramente discursiva); la fuerza la tiene el mejor argumento, ${ }^{114}$ no el más "consensuado", por lo que la ley no constituye un límite al trabajo de la dogmática, la cual es capaz de poner de relieve la incorrección de la ley (por su falta de ajuste a la naturaleza de las cosas). Dicho esto, en tercer y último lugar, el planteamiento de RADBRUCH deja abierta una cuestión que hoy sigue siendo objeto de discusión, a saber, la intensidad del grado de vinculación de la dogmática al sustrato social. ${ }^{115}$

\footnotetext{
108 RadBRUCH, Die Natur der Sache als juristische Denkform, 1964, p. 37, cita un pasaje de BINDING en el que queda claro el rechazo de la capacidad de rendimiento de la "naturaleza de las cosas” para este autor: „So wichtig die Lebensverhältnisse für das Verständnis der Rechtssätze sind, so unrichtig ist die oft aufgestellte Behauptung, es ließen sich die Rechtssätze unmittelbar aus ihnen, aus der sogenannten Natur der Sache ableiten, sie sei eine Rechtsquelle oder wenigstens bindend für den Gesetzgeber. Aus ihr folge z.B. daß mit dem Untergang der Sache das Eigentum daran erloschen, aus ihr, daß jeder Mensch geborene Person sei und daß in der Ehe der Mann zu regieren habe. Allein kein Lebensverhältnis regelt sich von selbst, und was man der N.d.S. folgen heißt, ist entweder Folgerung aus der juristischen Natur der Ehe oder des Eigentumsrechts, oder es ist Findung eines Rechtssatzes per analogiam, oder es ist die subjektive Rechtsansicht dessen, der seine Weisheit für die esoterische Weisheit der Dinge selbst hält“(el resaltado es mío).

${ }^{109}$ Como hacía vON LiszT ("la construcción del concepto de delito tiene que recurrir a la acción natural”, citado por RADBRUCH, Die Natur der Sache als juristische Denkform, 1964, p. 38).

${ }^{110}$ En contra EMGE, «Bekenntnis zu Gustav Radbruch», en KAUFMANN, Arthur (ed.), Gedächtnisschrift für Gustav Radbruch, 21.11.1878-23.11.1949, 1968, p. 44.

111 RADBRUCH, Die Natur der Sache als juristische Denkform, 1964, p. 13; EL MISMO, Vorschule der Rechtsphilosophie, $2^{\text {a }}$ ed., 1959, p. 22.

112 RADBRUCH, Die Natur der Sache als juristische Denkform, 1964, p. 39.

${ }^{113}$ Por lo que limitaría también la libertad del legislador, que estaría atado a un concepto material de delito que le viene dado (RoBles PlanAS, en EL MISMo, Límites al Derecho penal, pp. 19 ss.) y, por tanto, generaría solamente una ley legítima si respeta aquel concepto.

114 SILVA SÁNCHEZ, Aproximación al Derecho penal contemporáneo, $2^{\mathrm{a}}$ ed., 2010, III, adenda 2010, 3.

115 Cfr. las reflexiones de SiLVA SÁNCHEZ, LH-Roxin, 1997, pp. 28 s., sobre el problema de los límites ontológicos (entendidos en sentido fuerte o en sentido débil) a la labor de la dogmática jurídico-penal, el problema de cuánta libertad tiene la dogmática en su elaboración conceptual normativa (p. 29).
} 


\subsection{El rechazo del formalismo y del positivismo hermenéutico}

Así las cosas, tiene pleno sentido que RADBRUCH rechace, en la ciencia jurídica, el formalismo y, con ello, el positivismo (hermenéutico), esto es, una autocomprensión de la ciencia jurídica como avalorativa y esclava de la ley. En efecto, para RADBRUCH, el formalismo obedece a una visión estática del Derecho cuyo intérprete hace "filología". ${ }^{116}$ Ello se debe a que el positivismo hermenéutico entiende que las consideraciones de valor del Derecho son acientíficas: esa es la razón por la que dicho positivismo sustituye la Filosofía del Derecho por una Teoría general del Derecho dirigida a construir, a partir de ordenamientos jurídicos positivos, concretos conceptos generales comunes para el ordenamiento jurídico. Y eso redunda en una visión que reduce al intérprete, al juez, a la boca que pronuncia las palabras de la ley (MONSTESQUiEU), con el grave problema de que dicha hermenéutica se presenta como avalorativa pero acaba encubriendo decisiones de valor. ${ }^{117}$

Pues bien, RADBRUCH llega a afirmar que la Teoría general del Derecho constituye la "eutanasia de la Filosofía del Derecho" - "eutanasia” porque cuando irrumpe el positivismo, la Filosofía del Derecho ya estaba, según RADBRUCH, bastante herida por el historicismo (SAVIGNY, PUCHTA), el hegelianismo y el materialismo (MARX, ENGELS) - ${ }^{118}$ Para RADBRUCH el camino correcto es el del finalismo, la teleología, conforme al cual el Derecho está al servicio de las necesidades de la vida social, espiritual y moral, un planteamiento que requiere Filosofía y no filología. ${ }^{119}$ Los conceptos del Derecho - afirma RADBRUCH - no son propiedad "casual" de un ordenamiento jurídico concreto, sino presupuestos necesarios para que un ordenamiento pueda ser concebido como "ordenamiento jurídico" y, por ello, no pueden ser construidos inductivamente, sino determinados apriorísticamente. Ello explica, por una parte, su crítica al formalismo de la Escuela Histórica del Derecho (SAVIGNY), que sustituye la filosofía por la perspectiva histórica, quebrando el vínculo entre Derecho y cultura. Y, por otra, su rechazo de la visión del juez como "ser inanimado". Al respecto, RADBRUCH afirma que, ciertamente, el principio de la separación de poderes ha de llevar a diferenciar la labor del legislador y la del juez (y, con ella, la de la ciencia jurídica), pero que dicha división no consiste en atribuir al legislador la creación del Derecho y al juez su aplicación, sino que la división se produce "dentro de la creación del Derecho": ${ }^{120}$ la creación de Derecho del juez solamente tendría validez, a diferencia de lo que ocurre con la del legislador, para el caso concreto. "Jurisprudencia y ciencia del Derecho han seguido siendo, pese a la doctrina de la separación de poderes, creadoras de Derecho y siempre lo serán, y los juristas

\footnotetext{
${ }^{116}$ RADBRUCH, «Rechtswissenschaft als Rechtsschöpfung. Ein Beitrag zur juristischen Methodenstreit», ASS, 1905, pp. 355, 358.

${ }^{117}$ SILVA SÁNCHEZ, Aproximación al Derecho penal contemporáneo, $2^{\mathrm{a}}$ ed., 2010, III.4.C.b.

${ }^{118}$ RADBRUCH, Rechtsphilosophie, 2003, § 3, núm. 5, p. 27. RADBRUCH se refiere a la "lógica”, pero no en el sentido de la lógica formal (deducción o conceptos clasificatorios), ni en el sentido de la sistemática lógicoobjetiva (sachlogische Systematik), sino en el sentido de una lógica teleológica. Cfr. respecto a las diversas lógicas desde las cuales construir el sistema, RADBRUCH, «Zur Systematik der Verbrechenslehre», en HEGLER/GRÜNHUT, Festgabe für Reinhard von Frank zum 70. Geburtstag 16. August 1930, 1930, p. 159.

${ }^{119}$ RADBRUCH, Vorschule der Rechtsphilosophie, 2a ed., 1959, pp. 63 ss., 67.

${ }^{120}$ Con razón se ha subrayado la relación de RADBRUCH con la Freirrechtsbewegung (KANTOROwICZ, FUCHS, etc.). Cfr. al respecto FoulKES, "Gustav Radbruch in den ersten Jahrzehnten der Freirechtsbewegung», en KAUFMANN, Arthur (ed.), Gedächtnisschrift für Gustav Radbruch, 21.11.1878-23.11.1949, 1968, pp. 234 s.
} 
de hoy se diferencian solo de los juristas de antes y, esperemos, de los juristas del futuro en que aquel oculta lo que los otros admitían abiertamente”. ${ }^{121}$

Sobra decir que esta discusión es, todavía hoy, actual. Seguimos reflexionando sobre el papel de la dogmática jurídico-penal en el marco del ordenamiento jurídico y sobre la validez de sus juicios de valor. Paulatinamente, nos hemos convencido de que sería cómodo pero incorrecto ver al juez como un filólogo y que el principio de legalidad no tiene el extenso alcance que pretendía otorgarle la Ilustración, en una ilusión de plena legitimación democrática del Derecho penal. Entre este último y la ley penal existe una gran distancia que cubre la dogmática con su labor valorativa.

\subsection{La relación entre ciencia jurídica y Derecho positivo}

Ahora bien, ¿qué alcance tiene en RADBRUCH la independencia de la ciencia jurídica respecto al Derecho positivo? De entrada, RADBRUCH define la dogmática como ciencia sistemática "del sentido objetivo de los ordenamientos jurídicos positivos": por una parte, su objeto es el Derecho positivo vigente en cuanto obra humana, no el Derecho correcto, el "concepto de Derecho", del que se ocupa la Filosofía del Derecho; ${ }^{122}$ por otra, su tarea es averiguar el sentido objetivo del Derecho, no el sentido subjetivo que le atribuyó el legislador. ${ }^{123}$ Obviamente, la pregunta esencial es si en su concepción es posible una dogmática supranacional más allá del Derecho positivo de un Estado, ${ }^{124}$ es decir, si la dogmática puede definir el "deber ser" de la imputación, en el marco del contexto social previamente dado, sin coincidir con las previsiones del Derecho positivo. O, formulado quizá de modo más preciso, la duda no sería tanto si la dogmática puede formular los criterios de imputación al margen de la ley positiva, sino si ello sería, en la concepción de RADBRUCH, ciencia del Derecho o, más bien, Filosofía del Derecho penal.

Esa duda cobra especial fuerza cuando se atiende a cómo define RADBRUCH los tres niveles de la ciencia del Derecho: interpretación, construcción y sistema. Veámoslos con detenimiento. La interpretación se dirige a la averiguación del "sentido objetivamente válido del enunciado jurídico", que puede diferir del sentido subjetivo (psicológicamente constatable) que el legislador atribuyó a la ley. Por ello, la interpretación jurídica supera la interpretación filológica, es interpretación lógica de la ley. ${ }^{125}$ Las reglas lógicas aplicables a la interpretación jurídica derivan de contemplar el Derecho como "Kulturerscheinung" que tiene el sentido de realizar la idea de Derecho. ${ }^{126}$ Para RADBRUCH, los enunciados jurídicos son imperativos, expresión de un querer, pero el "sentido objetivo de un querer es un deber ser"; por ello, se puede decir que, si bien el objeto de la ciencia del Derecho son hechos (facta), el objeto propio de una "ciencia del ser", el método es el propio de una ciencia normativa (Normwissenschaft), es decir, la ciencia del Derecho

\footnotetext{
${ }^{121}$ RADBRUCH, ASS, 1905, p. 364: “Rechtsprechung und Rechtswissenschaft sind trotz der Gewaltenteilungslehre immer rechtsschöpferisch geblieben und werden es immer bleiben, und nur darin unterscheidet sich der heutige vom ehemaligen und hoffentlich auch vom zukünftigen Juristen, dass er verbirgt, was jene offen zugestehen“.

${ }^{122}$ En esto se diferencia la Ciencia del Derecho de la Filosofía del Derecho (ciencia del fin del Derecho) y de la Política jurídica (ciencia de los medios para alcanzar dicho fin). Cfr. con más detalle en RADBRUCH, Rechtsphilosophie, 2003, § 15, pp. 106 ss.

${ }^{123}$ RADBRUCH, ASS, 1905, pp. 359 ss.

${ }^{124}$ Silva SÁnCHEZ, Aproximación al Derecho penal contemporáneo, $2^{\mathrm{a}}$ ed., 2010, III.4.C.c.

${ }^{125}$ RADBRUCH, ASS, 1905, p. 363; EL MISMO, Rechtsphilosophie, 2003, § 15, pp. 108 ss., 113.

${ }^{126}$ RADBRUCH, Rechtsphilosophie, 2003, § 15, p. 113.
} 
no se interesa por los hechos en cuanto tales, sino por su sentido objetivo. ${ }^{127}$ A partir de aquí, la ciencia del Derecho - "construcción" cuando se refiere a un instituto jurídico y "sistema" cuando se refiere a todo un ordenamiento jurídico - tiene la tarea de elaborar su materia en dos sentidos: (i) la elaboración categorial de su materia, esto es, exponer el Derecho como realización del concepto de Derecho y sus categorías jurídicas; a este nivel pertenece, en Derecho penal, la teoría de las normas; (ii) y, además, la elaboración teleológica, fruto de contemplar el Derecho como intento de realizar la idea de Derecho; de esta elaboración forma parte, en Derecho penal, la teoría del fin de la pena. En este plano, la dogmática toma los conceptos extrajurídicos y los remodela teleológicamente. ${ }^{128}$

Así las cosas, parece adecuado concluir que RADBRUCH concibe la ciencia del Derecho como vinculada al Derecho positivo en el sentido de que este le proporciona la materia a elaborar categorial y teleológicamente. Ello no implica en ningún caso reducir la dogmática a filología, pero sí implica que el Derecho positivo definiría un coto en el que la dogmática busca el sentido objetivo de la ley partiendo de la idea de Derecho, interpreta y construye el sistema con el referente del valor, lo cual le permite ser crítica con dicho Derecho positivo (esto es, determinar si logra o no realizar la idea de Derecho). La ciencia del Derecho diferencia hechos relevantes e irrelevantes de la mano del criterio de la "relación de valor": solamente tiene en cuenta los hechos que son realizaciones, frustraciones, favorecimientos o impedimentos del valor al cual está orientado. ${ }^{129}$ Esto implica que el objeto de la ciencia jurídica puede cambiar, en la medida en que esta está referida al valor que orienta al Derecho y dicho valor no es inmutable: cada época tiene que escribir (o reescribir) su ciencia jurídica de nuevo, sin que ello le prive a esta última de su carácter de ciencia.

\subsection{El sistema del delito como sistema abierto: de los conceptos clasificatorios a los "Typenbegriffe"}

En sus inicios, RADBRUCH fue partidario del sistema clasificatorio de su maestro VON LISZT, como muestra su escrito de habilitación de 1903 (Der Handlungsbegriff in seiner Bedeutung für das Strafrechtssystem), pero progresivamente se alejó de dicho sistema, pasando a abrazar un sistema abierto. Muestra de ello es que en 1930, en la Festgabe für Frank, rechaza abiertamente el concepto de acción de von LiszT y, con ello, sus propias tesis de $1903 .{ }^{130}$ Pero ¿por qué abandona RADBRUCH el sistema clasificatorio? Según SCHMIDHÄUSER dicho abandono era, por una parte, el "paso" lógico a la vista de sus conclusiones en su investigación sobre el concepto de acción. Así, en su habilitación RADBRUCH había sostenido que el sistema de la acción y el de la omisión están plenamente separados, son sistemas paralelos, ${ }^{131}$ siendo su único vínculo el “concepto formal de

\footnotetext{
${ }^{127}$ RADBRUCH, Rechtsphilosophie, 2003, § 15, pp. 115 s.

${ }^{128}$ RADBRUCH, Rechtsphilosophie, 2003, § 15, p. 115.

${ }^{129}$ RADBRUCH, Rechtsphilosophie, 2003, § 15, p. 116.

${ }^{130}$ En efecto, RADBRUCH afirma que el concepto naturalístico de acción no sirve como "piedra angular" del sistema del delito y que el concepto fundamental de la teoría del delito es la realización del tipo, FrankFestgabe, p. 162; EL MISMO, Die Natur der Sache als juristische Denkform (FS-Laun, 1948), citado por la Sonderausgabe de 1964, Darmstadt.

${ }^{131}$ Cfr. el análisis de SCHMIDHÄUSER, «Zur Systematik der Verbrechenslehre. Ein Grundthema Radbruchs aus der Sicht der neueren Strafrechtsdogmatik», en KAUFMANN, Arthur (ed.), Gedächtnisschrift für Gustav Radbruch, 21.11.1878-23.11.1949, 1968, p. 269. El concepto de acción defendido por RADBRUCH en aquel entonces se aproximaba clarísimamente al concepto de vON LISZT y BELING (Cfr. WoLfF, «Das Problem der
} 
delito como tipo al que el ordenamiento vincula la pena como consecuencia jurídica" ${ }^{132}$ Esa conclusión constituía precisamente la prueba del fracaso de la sistemática clasificatoria, ${ }^{133}$ ya que el "sistema" no había sido capaz de procesar acción y omisión. Por otra parte, la tendencia general del Derecho penal de principios de la década de 1930 a abandonar el concepto formal de delito y a definirlo conforme a su contenido disvalioso tuvo su influencia en RADBRUCH.

Pues bien, el RADBRUCH de los años 30 define la construcción jurídica como "Synthese der herausanalysierten Elemente eines Rechtsgebildes”, es decir, una síntesis de los elementos del Derecho que han sido previamente separados mediante el análisis. ${ }^{134}$ El punto de partida es la naturaleza de las cosas y su influencia en la idea de Derecho (Stoffbestimmtheit der Rechtsidee). En la construcción jurídica se produciría una "progresiva transformación de una relación vital en una relación jurídica y de una relación jurídica en un instituto jurídico", ${ }^{135}$ un modo de ver las cosas inspirado en la teoría de los Typenbegriffe de Max WeBER. Para RADBRUCH, los conceptos clasificatorios (Klassenbegriffe o Gattungsbegriffe), construidos mediante la abstracción a partir de casos concretos, no sirven para la construcción jurídica, pues están al servicio de lo general, cuando en la construcción jurídica no interesa lo general sino lo esencial. ${ }^{136}$ Para trabajar con lo esencial es necesario construir Typenbegriffe, un término que alude a la idea de "tipos" no en el sentido de los tipos "ideales" como opuestos a los tipos "empíricos" (JELLINEK), sino en el sentido de Max WEBER, esto es, como "esquemas ideales de una realidad depurada de las casualidades individuales", construida coherentemente. ${ }^{137}$ En dichos "tipos" se recoge "lo esencial”, es decir, "el sentido de las fenómenos empíricos", una esencia que no se construye mediante la inducción a partir de muchos casos, sino que se puede extraer (como hace el juez) de un único caso que sea apropiado para ello. ${ }^{138} \mathrm{El}$ contenido de sentido de un factum se extrae poniendo dicho factum en relación con una idea (Sollen): el sentido se entiende así como "el Sollen realizado en el ser, el valor que se manifiesta en la realidad". ${ }^{139}$ El sentido, pues, no se encuentra en el mundo de la realidad, sino en el mundo del valor, el cual proporciona la idea que da sentido al fenómeno empírico. En realidad, este modo de ver la construcción conceptual no sorprende, pues armoniza perfectamente con la visión de RADBRUCH de la naturaleza de las cosas, una naturaleza imputada, fruto de atribuir un sentido a una realidad social, no inherente a la realidad misma (el valor se atribuye, no se “descubre").

Handlung im Strafrech», en KAUFMANN, Arthur (ed.), Gedächtnisschrift für Gustav Radbruch, 21.11.187823.11.1949, 1968, p. 293).

${ }^{132}$ RADBRUCH, Der Handlungsbegriff in seiner Bedeutung für das Strafrechtssystem, 1903, p. 143.

133 SCHMIDHÄUSER, GS-Radbruch, pp. $270 \mathrm{~s}$.

${ }^{134}$ RADBRUCH, Die Natur der Sache als juristische Denkform, 1964, pp. 31 ss.

${ }^{135}$ RADBRUCH, Die Natur der Sache als juristische Denkform, 1964, p. 31.

${ }^{136}$ Cfr. sobre la búsqueda de la “esencia” (y no de la “definición”) ya en la jurisprudencia de la Antigüedad y después en la Escolástica (Tomás DE AQUINO) Arthur KAUFMANN, Beiträge zur juristischen Hermeneutik sowie weitere rechtsphilosophische Abhandlungen, $2^{\text {a }}$ ed., 1993, pp. 55 s., con referencias al trabajo de NöRR. KAUFMANN explica claramente cómo el giro hacia lo apriorístico se produce con KANT (die "Jagdt" nach der Definition), quien dejó una impronta esencial en la ciencia jurídica; antes no existía una pretensión de definición, sistematización y clasificación matemáticas, sino de encontrar la esencia de las cosas.

137 "ideale Schemata einer von individuellen Zufälligkeiten gereinigten, folgerichtig durchkonstruierten und deshalb einseitig gesteigerten Wirklichkeit”, citado por RADBRUCH, «Klassenbegriffe und Ordnungsbegriffe im Rechtsdenken», Revue Internationale de la Théorie du Droit, (12), 1938, p. 48.

${ }^{138}$ RADBRUCH, Die Natur der Sache als juristische Denkform, 1964, pp. 31, 32.

${ }^{139}$ RADBRUCH, Die Natur der Sache als juristische Denkform, 1964, p. 33. 
Por ello, tiene sentido que, en RADBRUCH la construcción jurídica no consista en subsumir casos en conceptos clasificatorios (fruto de la abstracción de lo común a muchos casos = generalización), sino en la subsunción entre Typenbegriffe (fruto de la definición de lo esencial, del contenido de sentido), esto es, en determinar cuán próximo está un caso a una esencia. Nótese que ello no solamente implica superar el hermetismo del sistema cerrado (la "apertura" a las exigencias de la naturaleza de las cosas, que no porta en sí el sentido pero "pide" una atribución de sentido), sino además acentuar que en la construcción jurídica lo relevante es la esencia (el sentido), no la abstracción de lo común. ${ }^{140}$

Para RADBRUCH, los conceptos clasificatorios, provenientes de la lógica tradicional, obedecen a un pensamiento separador, diseccionan la realidad, conducen a una repuesta "sí o no". En cambio, los conceptos ordenadores no están integrados por elementos que se dan o no en un fenómeno concreto (y, por ello, no exigen como respuesta un sí o un no), sino por elementos que se dan en mayor o menor medida en el fenómeno en cuestión (y, por ello, permiten como respuesta el más y el menos). Los conceptos ordenadores son, por ello, adecuados para formular comparaciones y, a partir de estas, ordenar los fenómenos en escalas de las que se puede extraer un "esquema de grados”, llegando así a los conceptos tipológicos (Typenbegriffe). ${ }^{141}$ Así el sistema clasificatorio cerrado "ignora las notas intermedias" ${ }^{142}$ y, por ello, resulta inadecuado para "procesar" la realidad a la que debe ser aplicada. Es más, como ha indicado SILVA SÁnCHEZ, el sistema cerrado puede convertirse en un obstáculo, lo cual explicaría que, en ocasiones, en nuestra jurisprudencia se invierta el orden lógico de las sentencias. ${ }^{143}$

Ahora bien, la apertura o dinamización del sistema incorporando conceptos ordenadores no significa en absoluto la dilución del sistema. Se trata de construir un sistema que, sin renunciar a una idea apriorística de Derecho, sea suficientemente flexible - podríamos decir: poroso-, para continuar desarrollándose a partir de las exigencias de la realidad, de la "naturaleza de las cosas" (cambiante, históricamente condicionada). Ese objetivo no se puede alcanzar con meras correcciones del sistema clasificatorio, consistentes en añadir "conceptos clasificatorios específicos" (como la "semiimputabilidad"). ${ }^{144}$ Son necesarios conceptos tipológicos, ordenadores, que no son separadores, sino graduales, es decir, que permiten una "subsunción cuantitativamente graduable" porque "gehen durch verschwimmende Grenzen ineinander", ${ }^{145}$ así que pueden procesar mejor los fenómenos. ${ }^{146}$ Pues bien, esta graduabilidad también puede

\footnotetext{
${ }^{140}$ RADBRUCH, Die Natur der Sache als juristische Denkform, 1964, p. 35. Estas consideraciones se encuentran en perfecta armonía con su rechazo de la Teoría general del Derecho.

${ }^{141}$ RADBRUCH, Revue Internationale de la Théorie du Droit, (12), 1938, pp. 46 s. Cfr. al respecto GraCIA MARTín, «Crítica de las modernas construcciones de una mal llamada responsabilidad penal de la persona jurídica», RECPC, (18-05), 2016, pp. 36 s.

${ }^{142}$ RADBRUCH, Revue Internationale de la Théorie du Droit, (12), 1938, p. 49.

${ }^{143}$ Silva SÁnCHEZ, «Retos científicos y retos políticos de la ciencia del Derecho penal», RDPC, (9), 2002, p. 34.

${ }^{144}$ RADBRUCH, Revue Internationale de la Théorie du Droit, (12), 1938, p. 50.

${ }^{145}$ RADBRUCH, Revue Internationale de la Théorie du Droit, (12), 1938, p. 47.

${ }^{146}$ RADBRUCH, Frank-Festgabe, p. 172. SiLVA SÁNCHEZ, RDPC, (9), 2002, p. 34: “solo un sistema abierto, flexible, puede orientar la actividad judicial. Y que, por ello mismo, solo un sistema que, sin perder la coherencia interna, las relaciones estructurales de sus elementos, admita su progresiva modificación en función de los cambios de su objeto y de las necesidades aplicativas, puede constituir un marco de consenso mínimo entre el modelo continental y el anglosajón. En definitiva, cabría concluir que el sistema estructurado del delito
} 
predicarse del concepto de delito - en el que se basa precisamente la determinación de la pena: entre el delito y el no-delito existe un "fließender Übergang” y los conceptos clasificatorios implican, en cierta medida, detener ese proceso en un punto concreto (“congelarlo"), cuando la realidad exigiría más matices que solamente se pueden formular a partir de conceptos ordenadores. Los conceptos ordenadores son, en realidad, "conceptos clasificatorios in statu nascendi", pero su virtud es precisamente que se encuentran permanentemente en dicho "statu nascendi" ${ }^{147} \sin$ agarrotarse.

La relevancia de este planteamiento es evidente para la dogmática jurídico-penal: el sistema abierto a la realidad que es, por una parte, sistema, pero por otra parte poroso y flexible, dispuesto a absorber las exigencias del caso. Esto implica un abandono de una visión apriorística del sistema del delito que define un molde en el que hay que encajar el caso y, en cambio, se pregunta por la esencia de las cosas y su relevancia normativa para la definición precisa del delito. El camino esbozado por RADBRUCH, que ha dejado claras huellas en nuestra visión actual del sistema del delito, no solo permite que este último tenga mayor capacidad para responder a las exigencias del caso, sino que además sea de por sí capaz de evolucionar, una evolución que no era posible - por lo menos no en ese sentido - en un sistema cerrado que buscaba únicamente su perfeccionamiento mediante una reflexión puramente apriorística.

\section{Balance: la herencia de Radbruch para la dogmática jurídico-penal}

\subsection{La vuelta del valor a la dogmática y la orientación teleológica}

Lo dicho hasta ahora sirve para subrayar la impronta de este autor neokantiano en la visión actual de la dogmática. En primer lugar, RADBRUCH, junto a otros neokantianos, impulsa la "modificación esencial de los términos del sistema del Derecho penal", al convertirse el "valor en referencia para el contenido de las categorías sistemáticas”. ${ }^{148}$ Así, el valor, que había sido expulsado de la ciencia del Derecho por el positivismo, es recuperado para la dogmática. Ciertamente, un valor no ontológico, relativo y, por ello, cambiante. Pero la dogmática se pasa a concebir como una discusión sobre el sentido (del delito, de la pena), no sobre la filología de la ley positiva.

En segundo lugar, su concepción teleológica de la construcción jurídica (desde la idea de Derecho y el fin del Derecho) conduce a una visión de la dogmática que no se interesa por la realidad en sí (hechos naturales) sino por su sentido desde el Derecho. Y el sentido se construye desde los fines del Derecho - los conceptos extrapenales deben, pues, ser remodelados en función de estos últimos-. Ello tiene dos consecuencias importantes. Por una parte, el abandono de la visión naturalística del delito: "no hay ningún elemento del tipo que no sea a la vez descriptivo y normativo: si un concepto prejurídico es elevado a concepto jurídico, dicho concepto adopta inevitablemente, también en el caso de ser originariamente puramente descriptivo, rasgos normativos". ${ }^{149}$ Por otra parte, que el sistema del delito solamente abarca los presupuestos de la

de tradición alemana podrá también subsistir como referencia para la cultura jurídica anglosajona en la medida en que consiga serlo para la aplicación del Derecho que tiene lugar en su propio ámbito”.

${ }^{147}$ RADBRUCH, Revue Internationale de la Théorie du Droit, (12), 1938, p. 53.

${ }^{148}$ SILVA SÁNCHEZ, Aproximación al Derecho penal contemporáneo, $2^{\mathrm{a}}$ ed., 2010, III.2.C.

${ }^{149}$ RADBRUCH, Frank-Festgabe, p. 167. La distinción es, pues, solamente didáctica. 
pena que tienen que ver con el merecimiento de pena del hecho o del autor ${ }^{150}$ y que el fin de la pena no solo impregna el concepto de delito, sino también la determinación de la pena como reflejo de la diferente medida del delito. ${ }^{151}$

Esta visión teleológica del sistema ha dejado su huella en la actual concepción normativista del delito. En efecto, el rechazo de la visión naturalística y descriptiva del delito y la concepción de este último como "sentido objetivo" (incluso lo aparentemente "descriptivo" tiene una dimensión normativa) ponen las bases de una concepción normativista del delito. Y lo interesante es que su planteamiento tiene las mismas luces y sombras que el normativismo actual: las luces, la entrada del valor en el Derecho penal, la visión del delito como sentido, no como naturaleza; las sombras, la dificultad de manejar esa dimensión de sentido, de determinarla, así como de dilucidar la compleja relación entre sentido y ontología.

A la vez, la conexión entre fines de la pena y sistema del delito propia del enfoque teleológico referido al valor, no a las consecuencias empíricas externas del Derecho penal- se ha consolidado en la doctrina: así, por ejemplo, con matices diversos, esta visión se encuentra en la construcción del sistema del delito a la luz de los fines político-criminales de la pena (Roxin, ${ }^{152}$ casi parafraseando a RADBRUCH), en la construcción del sistema del delito a partir del fin de la pena (JAKOBS) y, entre nosotros, en la construcción de Mir PUIG ${ }^{153}$ y SILVA SÁNCHEZ. ${ }^{154}$ Hay importantes discrepancias entre estos autores en lo que atañe a la determinación de dichos fines, su legitimación y sus límites. Pero el común denominador sería la orientación teleológica del sistema del delito, que abre la puerta a la normativización de la teoría del delito. ${ }^{155}$ En efecto, pese a que continuamos debatiendo sobre lo ontológico y lo axiológico (entre la "Stoff” y la "Form") ${ }^{156}$, se puede hablar de una constante que "está constituida, sin duda, por la referencia teleológica y por la consiguiente tendencia a una mayor o menor normativización de los conceptos jurídicopenales"; ; 157 la dogmática posterior a los neokantianos sigue por el camino de la normativización, con más o menos reflexión previa sobre el método. ${ }^{158}$ Así pues, en los neokantianos estaría la raíz

\footnotetext{
${ }^{150}$ RADBRUCH, Frank-Festgabe, pp. 170 s., 163.

151 RADBRUCH, Frank-Festgabe, pp. 171 s.: “Die Maßverschiedenheit der Strafe kann ja nur auf eine Maßverschiedenheit der Verbrechenseigenschaft der Tat, der Verbrechenseigenschaft des Täters gegründet werden. Es wird also für jeden der Strafzumessungsgründe (...) der systematische Ort in der Verbrechenslehre bestimmt, d.h. ein Verbrechensmerkmal aufgewiesen werden müssen, als dessen stärkere oder schwächere Graduierung es sich darstellt. “Así, en la determinación de la pena, la pregunta no es el "sí o no” de la pena, sino el "más o menos” pena, un "más o menos” que proviene de traducir todos los factores del caso relevantes para el merecimiento de pena en un marco penal concreto (RADBRUCH, Revue Internationale de la Théorie du Droit, (12), 1938, p. 53).

152 Roxin, GS-Radbruch, pp. 260 ss.; EL MISMO, Kriminalpolitik und Strafrechtssystem, 1973, pp. 33 ss.

${ }^{153}$ Mir PUIG, Función de la pena y teoría del delito en el Estado social y democrático de Derecho, $2^{a}$ ed. revisada, 1982 , pp. $41 \mathrm{~s}$.

154 SiLva SÁnchez, Aproximación al Derecho penal contemporáneo, $2^{\mathrm{a}}$ ed., 2010, III.4.C.c, quien sostiene una orientación teleológica, siendo el telos el valor, no las consecuencias empíricas externas al sistema del delito (Folgenorientierung, consecuencialismo). Cfr. también III.4.D.

155 SILVA SÁNCHEZ, Aproximación al Derecho penal contemporáneo, 2a ed., 2010, III.2.C.

${ }^{156}$ Esto lo diagnostica Roxin en 1968 en su valoración de la herencia de RADBRUCH (GS-Radbruch, p. 261), refiriéndose a la "Dialektik von Stoff und Form im Aufbau unserer Verbrechenslehre".

${ }^{157}$ SiLVA SÁnchEZ, Aproximación al Derecho penal contemporáneo, 2a ed., 2010, III.2.E, III.3.

${ }^{158}$ Así, Roxin, GS-Radbruch, p. 263, afirma, respecto a la normativización de la teoría del delito que “dieser Befund (ist) methodologisch noch kaum ausgewertet worden”.
} 
de una concepción mucho más autónoma de la dogmática: en efecto, la entrada del valor, la concentración en la dimensión de sentido del delito, la construcción del sentido desde los fines de la pena determinan que el espacio propio de la dogmática sea enorme, un espacio que, como indicaba, puede considerarse más o menos condicionado por lo ontológico, pero que supone un abandono radical de la visión "raquítica" de la dogmática que estaba vinculada a la concepción naturalística del delito.

\subsection{Las raíces del sistema abierto de Roxin en la concepción de Radbruch}

Puede decirse que la concepción del sistema del delito de RADBRUCH como sistema (sirve para "cohesionar sistemáticamente la materia dispar mediante la unidad de la idea" - "de(n) disparate(n) „Stoff” durch die Einheit der Idee systematish zusammenzuhalten”) abierto (conceptos ordenadores, determinación de la idea por la materia) es asumida claramente por Roxin. Este último concibe que las categorías del delito son "directrices normativas" cuyo "contenido" es el "conjunto de sus formas no reducibles a un único criterio material"; ${ }^{159}$ el sistema del delito es, en su opinión, un sistema descriptivo orientado a directrices normativas y está abierto a la realidad, en la medida en que contempla las peculiaridades de las diversas formas del comportamiento punible, en vez de intentar "meterlas en la horma del sistema". ${ }^{160}$ Así pues, RoXIN retoma la visión del sistema del delito de RADBRUCH. Parafraseando la metáfora de LASK que desempeña un papel central en la concepción de RADBRUCH de la naturaleza de las cosas, Roxin afirma que los criterios normativos (acción, injusto, culpabilidad), en el momento en que entra la materia del Derecho y se materializan, adoptan una forma distinta, al igual que la idea adopta formas distintas al realizarse en mármol o bronce. Y Roxin rechaza el sistema cerrado (no se trata de subsumir lógico-formalmente la materia en conceptos superiores abstractos) y entiende que hay que desarrollar los criterios normativos "en la materia del Derecho", entendida esta no como facticidad avalorativa, sino como una realidad "conformada por dimensiones de sentido". ${ }^{161}$ En conclusión, la tarea del sistema sería formular soluciones adecuadas para dicha materia y exponerlas de manera clara y ordenada en sus relaciones estructurales y normativas. Así las cosas, la impronta de RADBRUCH en RoXIN resulta evidente: la apertura del sistema a la política criminal (un sistema teleológico, al servicio de determinados valores) propia del

\footnotetext{
${ }^{159}$ RoxIn, GS-Radbruch, p. 264.

${ }^{160}$ Roxin, GS-Radbruch, pp. 264 s. Esa rigidez del sistema explicaría que la dogmática del delito imprudente sea mucho más burda, pues - afirma Roxin- la reducción de hecho doloso y hecho imprudente al criterio común de la causalidad condujo a olvidar las diferencias estructurales entre ambos. Y lo mismo podría decirse respecto a la omisión, que hasta GRÜNWALD y Armin KAUFMANN habría sido vista desde la perspectiva de los delitos de comisión.

${ }^{161}$ Roxin, GS-Radbruch, p. 265, asumiendo la visión de RADBRUCH: "Ein anderes ist die Idee, wenn sie in Marmor, ein anderes, wenn sie in Bronze verwirklicht werden soll. So nehmen auch die normativen Maßstäbe von Handlung, Unrecht und Schuld, wenn sie sich beim Eingehen in den Rechtsstoff materialisieren, eine verschiedene Gestalt an, je nachdem, ob es um Tun oder Unterlassen, um willentliches oder unwillentliches Handeln geht. Versuch, Teilnahme, Irrtum (...) erhalten bei gleicher normativer Konzeption eine abgewandelte, der differierenden Struktur des Rechtsstoffes angepaßte Ausprägung. Diese Stoffbestimmtheit der Idee wird immer dann sichtbar, wenn man nicht unter abstrakte Oberbegriffe formallogisch zu subsumieren versucht, sondern statt dessen, wie es bei systematischen Grundbegriffen allein fruchtbar ist, die normativen Maßstäbe am Rechtsstoff entfaltet; dabei bedarf es kaum Betonung, daß auch der „Rechtsstoff" nicht im Sinne einer wertfreien Faktizität, sondern als eine von Sinnbezügen durchformte Gegebenheit zu verstehen ist."
} 
planteamiento de este autor se remonta a la concepción definida por RADBRUCH y los neokantianos. ${ }^{162}$

\subsection{El puente entre Derecho continental y Derecho anglosajón}

No es casualidad que la concepción del sistema de RADBRUCH constituya una base para el entendimiento entre Derecho continental y Derecho anglosajón. Este autor conocía el Derecho anglosajón a fondo y, si bien no lo consideraba asumible en su totalidad, reconocía en él algo de lo que carecía el sistema clasificatorio cerrado: la apertura al caso, a la naturaleza de las cosas, a la realidad gradual. ${ }^{163}$ Su estudio del sistema cerrado, por una parte, y el case law, por otra, arroja luz sobre cómo cada uno de los dos extremos han descuidado algo esencial: el primero, la toma en consideración de la realidad para la que está pensado el Derecho; el segundo, el sistema (por haberse concentrado en la Teoría del Derecho, en construir conceptos "generales", en vez de en la construcción de conceptos "esenciales"). Pues bien, entre nosotros ha sido SILVA SÁncheZ quien ha puesto de relieve la capacidad de rendimiento de la visión de RADBRUCH para construir un puente entre la dogmática sistemática y el case law anglosajón. ${ }^{164}$

\subsection{La superación de la oposición entre dogmática y política criminal}

Con lo dicho hasta ahora, queda claro que la concepción de RADBRUCH del sistema del delito, como sistema teleológico concebido a partir de las finalidades de la pena, implica la superación de la oposición entre política criminal y sistema del delito que marcaba el planteamiento de voN LISZT. Significa el paso de un sistema categorial, basado en una sistemática lógico-objetiva (sachlogische Systematik), a un sistema teleológico que se quedó en nuestra visión del sistema, si bien hay un "paréntesis metodológico" en este desarrollo durante la época del finalismo, ${ }^{165}$ el cual pone lo lógico-objetivo por encima de lo teleológico. ${ }^{166}$ En efecto, Roxin retoma el método y la normativización propia del neokantismo ya claramente en 1968 (GS-Radbruch $)^{167}$ y en su obra Política criminal y sistema del Derecho penal, ${ }^{168}$ aunque admite algunos límites ontológicos

\footnotetext{
162 SiLVA SÁNCHEZ, LH-Roxin, 1997, pp. 22 ss., en su análisis del modelo de Roxin, aborda la cuestión del modo en que este concibe el valor propio de la Política criminal que orienta a la dogmática y, en concreto, la cuestión de si y cuánto principialismo y cuánto consecuencialismo hay en la concepción de Roxin, concluyendo que su concepción de la Política criminal no es “empírica” (consecuencialismo), sino valorativa.

163 Radbruch, Revue Internationale de la Théorie du Droit, (12), 1938, pp. 52 s.; EL mismo, Der Geist des englischen Rechts, 1956, pp. 23 ss.

${ }^{164}$ SiLVA SÁNCHEZ, RDPC, (9), 2002, pp. 83 ss.

${ }^{165}$ SILVA SÁNCHEZ, Aproximación al Derecho penal contemporáneo, $2^{\text {a }}$ ed., 2010, III.2.C, sobre el cambio radical de actitud epistemológica del finalismo (la ubicación del sentido en la ontología). En este sentido también SCHMIDHÄUSER, GS-Radbruch, p. 274: WELZEL vuelve a un sistema clasificatorio y al “Oberbegriff” de la acción -precisamente rechazado por RADBRUCH en la Festgabe-Frank en 1930-.

${ }^{166}$ SCHÜNEMANN, «La política criminal y el sistema de Derecho penal», ADPCP, 1991, pp. 701 s.: el finalismo habría vuelto a separar dogmática y política criminal, con la introducción de elementos ontológicos en la teoría del delito.

${ }^{167}$ Roxin, GS-Radbruch, p. 265 rechaza claramente el sistema clasificatorio-deductivo y asume el paradigma de RADBRUCH de los conceptos clasificatorios en un sistema abierto.

168 SCHÜNEMANN, «Einführung in das strafrechtliche Systemdenken», en EL MISMO (ed.) Grundfragen des modernen Strafrechtssystem, 1984, pp. 43 ss. Ya antes en Roxin, GS-Radbruch, p. 265.
} 
(menores que los del finalismo); después, JАКОBS llevará dicho normativismo al extremo, desprendiéndose prácticamente de lo ontológico. ${ }^{169}$

\subsection{El problema (de Radbruch y de la dogmática del presente) de los "valores" de referencia en la construcción dogmática}

El precio del relativismo valorativo de RADBRUCH, el precio a pagar para tener un sistema que resiste el paso del tiempo, es su vaciamiento de "valores concretos vinculantes" o "limitadores". Por eso SILVA SÁnCHEZ ha subrayado que el sistema del neokantismo, a consecuencia del relativismo axiológico, consiste en "fórmulas reguladoras (...) que no imponen un contenido normativo preciso". ${ }^{170}$ Ello implica, ciertamente, que el sistema no tiene límites materiales infranqueables, lo cual lo convierte en especialmente dúctil, en el que caben contenidos muy diversos, dependiendo de cuál sea el valor de referencia.

Así las cosas, un aspecto central de la discusión atañe al origen de los valores de referencia en la construcción dogmática. Ese es un aspecto que resulta complejo de resolver en el marco del pensamiento de RADBRUCH, pues, como se ha indicado antes, no está claro cómo se produce el paso del "valor subjetivo" del sujeto cognoscente al valor "relevante" para el Derecho (siendo discutible si al final RADBRUCH admitiría ciertos valores objetivos o, en cambio, solo valores intersubjetivos). Sea como fuere, los problemas epistemológicos no los tienen solamente quienes optan por una concepción ontológica del valor, sino también quienes han seguido un paradigma relativista. El problema esencial es acceder epistemológicamente a los “valores vigentes" en una sociedad y tiempo concreto (normatividad social), teniendo en cuenta el carácter plural de las sociedades y, previo a dicho problema, la cuestión de si es siquiera posible llevar a cabo una averiguación de los valores socialmente vigentes sin estar lastrado por el subjetivismo epistemológico del dogmático.

Pero lo que sí se puede afirmar es que hoy tenemos muy claro que la dogmática jurídico-penal debe realizar una valoración propia (limitada o no por lo ontológico y, por tanto, más o menos “libre”), que la ontología no puede "sustituir” la valoración jurídico-penal (¡ni las estructuras lógico-objetivas, ni la criminología crítica!) y que no existe una “dogmática neutral” (descriptiva) que pueda librarse del peso de justificar sus valoraciones.

\section{6. ¿“Autolimitación” de la dogmática a un Derecho positivo concreto?}

Por último, las consideraciones de RADBRUCH sobre la dogmática sugieren que este autor limita la ciencia del Derecho al marco de un sistema jurídico concreto, ${ }^{171} \sin$ que aquella pueda formular enunciados más allá de este último (eso sería tarea de la Filosofía del Derecho). Esta afirmación

\footnotetext{
${ }^{169}$ Recuérdese lo que indica SILVA SÁNCHEZ, Aproximación al Derecho penal contemporáneo, $2^{\mathrm{a}}$ ed., 2010, III.3: la pretensión de Roxin era más práctica que metodológica: su intención era "salvar” a un sistema que, en el contexto del finalismo, se había desentendido de sus efectos en la realidad y su relación con la política criminal. Es JАКоBS quien aborda el normativismo poniendo el acento en lo metodológico. Sobre las diferencias entre el normativismo de ROXIN y el de JAKOBS, SILVA SÁNCHEZ, LH-Roxin, 1997, p. 24, quien subraya que ЈАКоBS sí admitiría como límite ontológico el que viene dado por el fenómeno de la circularidad hermenéutica de los procesos de conocimiento humanos.

${ }^{170}$ SILVA SÁNCHEZ, Aproximación al Derecho penal contemporáneo, 2ª ed., 2010, III.2.C.

${ }^{171}$ RADBRUCH, Rechtsphilosophie, 2003, § 15, p. 116.
} 
genera la duda de si ello implica que la dogmática neokantiana de RADBRUCH se comprende a sí misma como un mero complemento del Derecho positivo (si "complemento" o "correctivo" se puede discutir). Nótese que de la respuesta a esta pregunta dependen cuestiones esenciales, como la posibilidad de una dogmática supranacional. Algunos autores han sostenido que la dogmática neokantiana vendría a ser un complemento del positivismo, en la medida en que, pese a establecer aquella una relación entre el ser y el valor, este último es contingente (y definido por el legislador mediante un acto de autoridad). Según esto, la dogmática neokantiana asumiría los valores del Derecho positivo, ofreciendo al positivismo las herramientas de las que este carecía (por operar prácticamente solo con "filología” en la interpretación de la ley). Así, la afirmación (expresa) de RADBRUCH conforme a la cual el objeto de la ciencia jurídica, de la dogmática, a saber, el ordenamiento jurídico puede cambiar, parece conducir a la conclusión de que la dogmática puede lograr "resultados" válidos para su objeto (un sistema jurídico concreto), pero no más allá de este último. Sin embargo, aunque es cierto que el relativismo valorativo de RADBRUCH no permite construir un sistema dogmático permanente e inmutable, debido al carácter cambiante del objeto de la dogmática, ello no significa que la dogmática de corte neokantiano sea "positivista" o "nacionalista". Ello sería erróneo, porque el referente para la ciencia del Derecho, la dogmática, no es el "enunciado jurídico en sí”, sino el "sentido objetivo de los enunciados”, sentido que no depende del querer del legislador, sino que se determina ( ¡atribuye!) teleológicamente, en concreto, a partir de la idea de Derecho. Lo decisivo es, en la dogmática de RADBRUCH, el "sentido objetivo de la ley atribuido desde la idea de Derecho", no la ley como voluntad de un legislador que ha "tomado" las decisiones valorativas. Por ello, no es cierto que RADBRUCH conciba la dogmática como lacayo del Derecho positivo. Este último es su referente, su “objeto", pero la dogmática está por encima del Derecho positivo. Que ello es así lo demuestra que RADBRUCH no define la "Zweckmässigkeit" en sentido positivista-instrumental, sino como referencia del Derecho a los valores jurídicos más elevados. ${ }^{172}$ Así pues, para RADBRUCH la dogmática es suprapositiva, aunque tenga como referente el Derecho positivo. Con todo, en RADBRUCH la dogmática sí depende del valor de referencia y, por tanto, sus contenidos se deben modificar en la medida en que dicho valor (el fin, como parte de la idea de Derecho) cambie. En conclusión, la dogmática no sería cambiante debido a su dependencia del Derecho positivo - en tal caso, sí sería el complemento del positivismo-, sino debido a su dependencia de un valor que se concibe como cambiante.

Ahora bien, surge la duda de si la dogmática puede ser crítica con los valores recogidos en el Derecho positivo. Al respecto, se ha discutido si el grado de crítica al legislador que RADBRUCH tolera en sus trabajos de postguerra es coherente con el grado de crítica que habría tolerado antes, en el marco de su relativismo valorativo. En efecto, la lectura de trabajos como la "Erneuerung des Rechts" o "Gesetzliches Unrecht und übergesetzliches Recht" sugieren la introducción de límites materiales que, en lo que aquí interesa, abren la puerta a la afirmación de que en la dogmática hay contenidos mínimos permanentes, algo que, como decía, no está claro que sea compatible con la concepción del primer RADBRUCH. ${ }^{173}$ Sobre ello se ha discutido mucho y a este problema he dedicado mi atención en otro lugar. ${ }^{174}$

\footnotetext{
${ }^{172}$ Neumann, en Härle/Vogel (eds.), „Vom Rechte, das mit uns geboren ist“. Aktuelle Probleme des Naturrechts, 2007, p. 15.

${ }^{173}$ Neumann, en HÄrle/Vogel (eds.), „Vom Rechte, das mit uns geboren ist“. Aktuelle Probleme des Naturrechts, 2007, pp. 13 ss.

174 PASTOR MuÑOZ, ARSP, (4), 2018, pp. 455 ss.
} 
Con ello pongo fin a estas líneas. Lo expuesto aquí es solamente una aproximación a algunos de los muchos aspectos de la inmensa obra de Gustav RADBRUCH que pretende subrayar que la comprensión del pensamiento de los neokantianos y, en este caso, de RADBRUCH, nos puede ayudar a comprender mejor los problemas a los que se enfrenta la dogmática actual (el problema del valor, las cuestiones de método, los límites al normativismo) y las cuestiones relativas a su propia identidad (su relación con el Derecho positivo y la posibilidad de una dogmática supranacional o suprapositiva, su relación con la política criminal, etc.).

\section{Bibliografía}

BARATTA (1983), «Valores y método jurídico en el positivismo penal alemán», en CHIAPPINI, Problemas de Derecho penal, Rubinzal Culzoni, Santa Fe, 1983, pp. 233 ss.

(1968), "Gedanken zu einer dialektischen Lehre der Natur der Sache», en KAUfMANN, Arthur (ed.), Gedächtnisschrift für Gustav Radbruch, 21.11.1878-23.11.1949, Vandenhoeck und Ruprecht, Gotinga, pp. 173 ss.

CATtANeO (1968), "Gustav Radbruch als Theoretiker und Verteidiger des Rechtsstaats», en KAUFMANN, Arthur (ed.), Gedächtnisschrift für Gustav Radbruch, 21.11.1878-23.11.1949, Vandenhoeck und Ruprecht, Gotinga, pp. 182 ss.

EMGE (1968), «Benenntnis zu Gustav Radbruch», en KaUfMANN, Arthur (ed.), Gedächtnisschrift für Gustav Radbruch, 21.11.1878-23.11.1949, Vandenhoeck und Ruprecht, Gotinga, pp. 44 ss.

ENGISCH (1968), «Gustav Radbruch als Rechtsphilosoph», en KAUFMAnN, Arthur (ed.), Gedächtnisschrift für Gustav Radbruch, 21.11.1878-23.11.1949, Vandenhoeck und Ruprecht, Gotinga, pp. 60 ss.

FECHNER (1968), "Naturrecht heute», en KaUfMANN, Arthur (ed.), Gedächtnisschrift für Gustav Radbruch, 21.11.1878-23.11.1949, Vandenhoeck und Ruprecht, Gotinga, pp. 161 ss.

GolDSCHMIDT, Werner (1968), "Erkenntnis und Bekenntnis», en KaUFMANN, Arthur (ed.), Gedächtnisschrift für Gustav Radbruch, 21.11.1878-23.11.1949, Vandenhoeck und Ruprecht, Gotinga, pp. 93 ss.

GRACIA MARTín (2016), "Crítica de las modernas construcciones de una mal llamada responsabilidad penal de la persona jurídica», Revista Electrónica de Ciencia Penal y Criminología, (18-05), 2016 (http://criminet.ugr.es/recpc/18/recpc18-05.pdf)

HASSEMER (1968), «Die rechtstheoretische Bedeutung des gesetzlichen Strafrahmens. Bemerkungen zu Radbruchs Lehre von den Ordnungsbegriffen», en KaUfMANN, Arthur (ed.), Gedächtnisschrift für Gustav Radbruch, 21.11.1878-23.11.1949, Vandenhoeck und Ruprecht, Gotinga, pp. 281 ss.

HAUSER (1968), «Die verborgene Lebenslinie. Gustav Radbruch und die Religion», en KAUFMANN, Arthur (ed.), Gedächtnisschrift für Gustav Radbruch, 21.11.1878-23.11.1949, Vandenhoeck und Ruprecht, Gotinga, pp. 50 ss. 
KaUfMANN, Arthur (1993), «Die »ipsa res iusta«. Gedanken zu einer hermeneutischen Rechtsontologie», en EL MISMO, Beiträge zur juristischen Hermeneutik sowie weitere rechtsphilosophische Abhandlungen, $2^{\mathrm{a}}$ ed., Heymanns, Colonia, pp. 53 ss.

(1993), «Über den Zirkelschluss in der Rechtsfindung», en EL MISMO, Beiträge zur juristischen Hermeneutik sowie weitere rechtsphilosophische Abhandlungen, $2^{\mathrm{a}}$ ed., Heymanns, Colonia pp. 65 ss.

KIRSTE (2011), "Rechtsidee und Elemente der Gerechtigkeit bei Gustav Radbruch», en PAULY, (ed.), Rechts- und Staatsphilosophie des Relativismus. Pluralismus, Demokratie und Rechtsgeltung bei Gustav Radbruch, Baden-Baden, pp. 57 ss.

KLUG (1968), «Thesen zu einem kritischen Relativismus in der Rechtsphilosophie», en KaUfMANN, Arthur (ed.), Gedächtnisschrift für Gustav Radbruch, 21.11.1878-23.11.1949, Vandenhoeck und Ruprecht, Gotinga, pp. 103 ss.

LEICHT (1968), «Obrigkeitspositivismus und Widerstand», en KaUfMANN, Arthur (ed.), Gedächtnisschrift für Gustav Radbruch, 21.11.1878-23.11.1949, Vandenhoeck und Ruprecht, Gotinga, pp. 191 ss.

MARCIC (1968), "Gustav Radbruch und Hans Kelsen», en KAUFMANN, Arthur (ed.), Gedächtnisschrift für Gustav Radbruch, 21.11.1878-23.11.1949, Vandenhoeck und Ruprecht, Gotinga, pp. 82 ss.

Mir PUIG (1982), Función de la pena y teoría del delito en el Estado social y democrático de Derecho, $2^{\mathrm{a}}$ ed. revisada, Bosch, Barcelona.

NEUMANN (2020), «Rechtsphilosophie im Spiegel der Zeit: Gustav Radbruch (1878-1949)», Juristen Zeitung, (1), pp. 1 ss.

(2007), «Naturrecht und Positivismus im Denken Gustav Radbruchs. Kontinuitäten und Diskontinuitäten», en HÄrLE/VOGEL (eds.), „Vom Rechte, das mit uns geboren ist“. Aktuelle Probleme des Naturrechts, Herder, Friburgo, pp. 11 ss. (http://www.kas.de/upload/dokumente/verlagspublikationen/Naturrecht/Naturrecht_neu mann.pdf)

(1987), «Neue Entwicklungen im Bereich der Argumentationsmuster zur Begründung oder zum Ausschluss strafrechtlicher Verantwortlichkeit», Zeitschrift für die gesamte Strafrechtswissenschaft, (4), 1987, pp. 567 ss.

PASTOR MUÑOz (2018), «Was bleibt übrig von dem Gesetzlichkeitsprinzip in dem Völkerstrafrecht? Zugleich ein Beitrag über die Leistungsfähigkeit der Radbruchschen Formel», Archiv für Rechts- und Sozialphilosophie, (4), pp. 455 ss.

PaUl (1968), "Gustav Radbruchs Konzeption des sozialen Rechts und die marxistische Rechtstheorie», en KaUfmanN, Arthur (ed.), Gedächtnisschrift für Gustav Radbruch, 21.11.187823.11.1949, Vandenhoeck und Ruprecht, Gotinga, pp. 107 ss. 
RADBRUCH (2003), Rechtsphilosophie. Studienausgabe, $2^{\mathrm{a}}$ ed. (DreIER/PAUlSON), C. F. Müller, Heidelberg.

(1995), Gesamtausgabe, Band 7: Strafrecht, C. F. Müller, Heidelberg.

(1968), «Erneuerung des Rechts», en KAUfMANN, Arthur (ed.), Gedächtnisschrift für Gustav Radbruch, 21.11.1878-23.11.1949, Vandenhoeck und Ruprecht, Gotinga, pp. 26 ss.

(1964), Die Natur der Sache als juristische Denkform, citado conforme a la Sonderausgabe, Wissenschaftliche Buchgesellschaft, Darmstadt (primera publicación en HernMarck (ed.), Festschrift zu Ehren von Prof. Dr. Jur. Rudolf Laun, J. P. Toth, Hamburgo, 1948).

(1959), Vorschule der Rechtsphilosophie: Nachschrift einer Vorlesung, $2^{\text {a }}$ ed., Vandenhoeck \& Ruprecht, Gotinga.

(1958), Einführung in die Rechtswissenschaft, $9^{\mathrm{a}}$ ed., Koehler, Stuttgart.

(1957), Der Mensch im Recht, Vandenhoeck \& Ruprecht, Gotinga.

(1956), Der Geist des Englischen Rechts, Vandenhoeck \& Ruprecht, Gotinga.

(1938) «Klassenbegriffe und Ordnungsbegriffe im Rechtsdenken», Revue Internationale de la Théorie du Droit, (12), pp. 46 ss. Traducción al castellano de José Luis GUZMÁN DALBORA, «Conceptos de clasificación y conceptos ordenadores en el pensamiento jurídico», RECPC, (11-r3), 2009 (http://criminet.ugr.es/recpc/11/recpc11-r3.pdf).

(1930), «Zur Systematik der Verbrechenslehre», en HEGLER/GrÜNHUT, Festgabe für Reinhard von Frank zum 70. Geburtstag 16. August 1930, J. C. B. Mohr, Tubinga, pp. 158 ss.

(1905), «Rechtswissenschaft als Rechtsschöpfung. Ein Beitrag zur juristischen Methodenstreit», Archiv für Sozialwissenschaft und Sozialpolitik, 1905, pp. 355 ss.

(1903), Der Handlungsbegriff in seiner Bedeutung für das Strafrechtssystem, Guttentag, Berlin.

Roxin (1973), Kriminalpolitik und Strafrechtssystem, $2^{\text {a }}$ ed., de Gruyter, Berlin

(1968), «Einige Bemerkungen zum Verhältnis von Rechtsidee und Rechtsstoff in der Systematik unseres Strafrechts», en KaufmanN, Arthur (ed.), Gedächtnisschrift für Gustav Radbruch, 21.11.1878-23.11.1949, Vandenhoeck und Ruprecht, Gotinga, pp. 260 ss.

RoBles Planas (2019), «Normas de conducta», Indret. Revista para el análisis del Derecho, (1). 
- 2012), «Dogmática de los límites al Derecho penal», en voN HiRSCH/SeElmanN/WohleRs (ed. alemana)/Robles Planas (ed. española), Límites al Derecho penal. Principios operativos en la fundamentación del castigo, Atelier, Barcelona, pp. 19 ss.

(2010), «La identidad de la dogmática penal», Zeitschrift für Internationale Strafrechtsdogmatik, (2), pp. 134 ss. (también en RoBles PLANAS, Estudios de dogmática jurídico-penal. Fundamentos, teoría del delito y Derecho penal económico, BdeF, Buenos Aires, 2014, pp. 3 ss.); en alemán, «Das Wesen der Strafrechtsdogmatik», Zeitschrift für Internationale Strafrechtsdogmatik, (5), 2010, pp. 357 ss.

SCHÜNEMANN (1991), «La política criminal y el sistema de Derecho penal», Anuario de derecho penal y ciencias penales, (3), 1991, pp. 693 ss.

SCHMIDHÄUSER (1968), «Zur Systematik der Verbrechenslehre. Ein Grundthema Radbruchs aus der Sicht der neuen Strafrechtsdogmatik», en KaUfmanN, Arthur (ed.), Gedächtnisschrift für Gustav Radbruch, 21.11.1878-23.11.1949, Vandenhoeck und Ruprecht, Gotinga, pp. 268 ss.

SCHMidT (1968), "Gustav Radbruch und die Rechtsgeschichte», en Kaufmann, Arthur (ed.), Gedächtnisschrift für Gustav Radbruch, 21.11.1878-23.11.1949, Vandenhoeck und Ruprecht, Gotinga, pp. 243 ss.

SCHWARZSCHILD (1968), «Über Gerechtigkeit», en KAUFMANN, Arthur (ed.), Gedächtnisschrift für Gustav Radbruch, 21.11.1878-23.11.1949, Vandenhoeck und Ruprecht, Gotinga, pp. 69 ss.

Silva SÁnchez (2010), Aproximación al Derecho penal contemporáneo, $2^{\mathrm{a}}$ ed., BdeF, Buenos Aires/Montevideo.

(2002), «Retos científicos y retos políticos de la ciencia del Derecho penal», Revista de Derecho penal y Criminología, (9), pp. 83 ss.

(1997), «Política criminal en la dogmática: algunas cuestiones sobre su contenido y límites», en SILVA SÁNCHEZ (ed.), Política criminal y nuevo Derecho penal. Libro Homenaje a Claus Roxin, Bosch, Barcelona, pp. 17 ss.

(1995), «Sobre las posibilidades y límites de una dogmática supranacional», en SChÜNEMANN/FigueIREDo Dias (coord.)/Silva SÁncheZ (ed. española), Fundamentos de un sistema europeo de Derecho penal. Libro-Homenaje a Claus Roxin, Bosch, Barcelona, pp. 11 ss.

VerdROSS (1968), «Beständigkeit und Geschichtlichkeit im Recht», en KAUfMANN, Arthur (ed.), Gedächtnisschrift für Gustav Radbruch, 21.11.1878-23.11.1949, Vandenhoeck und Ruprecht, Gotinga, pp. 129 ss.

VON DER PFORDTEN (2002), «Die Rechtsidee bei Kant, Hegel, Stammler, Radbruch und Kaufmann», en SHING-I-Liu (ed.), Value, Pluralism, Tolerance and Law: in memoriam Professor Arthur Kaufmann, Taipei Wu-Nan Book Comp, pp. 333 ss. 
WAPLER (2011), «Wertrelativismus und Positivismus. Theoretische Grundlagen der Rechts- und Staatsphilosophie Gustav Radbruchs», en PAULY (ed.), Rechts- und Staatsphilosophie des Relativismus. Pluralismus, Demokratie und Rechtsgeltung bei Gustav Radbruch, Nomos, BadenBaden, pp. 33 ss.

(2008), Werte und das Recht. Individualistische und kollektivistische Deutungen des Wertbegriffs im Neukantismus, Nomos, Baden-Baden.

WoLF, Erik (1968), «Sich ins Rechte denken. Zu einem Leitwort Gustav Radbruchs», en KAUFMANN, Arthur (ed.), Gedächtnisschrift für Gustav Radbruch, 21.11.1878-23.11.1949, Vandenhoeck und Ruprecht, Gotinga, pp. 76 ss.

WolfF, Ernst Amadeus (1968), «Das Problem der Handlung im Strafrecht», en KaUfMANN, Arthur (ed.), Gedächtnisschrift für Gustav Radbruch, 21.11.1878-23.11.1949, Vandenhoeck und Ruprecht, Gotinga, pp. 291 ss.

WÜRTENBERGER (1968), «Zur Idee des „sozialen Rechts“ bei Gustav Radbruch», en KAUfMANN, Arthur (ed.), Gedächtnisschrift für Gustav Radbruch, 21.11.1878-23.11.1949, Vandenhoeck und Ruprecht, Gotinga, pp. 200 ss. 